\title{
Cell Cycle Regulation of the p34 ${ }^{\mathrm{cdc} 2}$ Inhibitory Kinases
}

\section{Sue Atherton-Fessler, ${ }^{*}+$ Feng Liu, $\uparrow \S$ Brian Gabrielli, $+\|$ Margaret S. Lee, ${ }^{*}+$ Cheng-Yuan Peng, $† \neq \S$ and Helen Piwnica-Wormst $\uparrow \S$}

\author{
*Department of Physiology, Tufts University School of Medicine, Boston, Massachusetts 02111; \\ †Beth Israel Hospital and Department of Microbiology and Molecular Biology, Harvard Medical \\ School, Boston, Massachusetts 02115; and ¥Committee on Virology, Harvard Medical School, \\ Boston, Massachusetts 02115
}

Submitted June 6, 1994; Accepted July 27, 1994

Monitoring Editor: Keith R. Yamamoto

In cells of higher eukaryotic organisms the activity of the $\mathrm{p} 34^{\mathrm{cdc} 2} /$ cyclin B complex is inhibited by phosphorylation of $\mathrm{p} 34^{\mathrm{cdc} 2}$ at two sites within its amino-terminus (threonine 14 and tyrosine 15). In this study, the cell cycle regulation of the kinases responsible for phosphorylating $\mathrm{p} 34^{\mathrm{cdc} 2}$ on Thr14 and Tyr15 was examined in extracts prepared from both HeLa cells and Xenopus eggs. Both Thr14- and Tyr15- specific kinase activities were regulated in a cell cycle-dependent manner. The kinase activities were high throughout interphase and diminished coincident with entry of cells into mitosis. In HeLa cells delayed in G2 by the DNA-binding dye Hoechst 33342, Thr14- and Tyr15- specific kinase activities remained high, suggesting that a decrease in Thr14- and Tyr15- kinase activities may be required for entry of cells into mitosis. Similar cell cycle regulation was observed for the Thr14/Tyr15 kinase(s) in Xenopus egg extracts. These results indicate that activation of CDC2 and entry of cells into mitosis is not triggered solely by activation of the Cdc25 phosphatase but by the balance between Thr14/Tyr15 kinase and phosphatase activities. Finally, we have detected two activities capable of phosphorylating p34 ${ }^{\text {cdc2 }}$ on Thr14 and/ or Tyr15 in interphase extracts prepared from Xenopus eggs. An activity capable of phosphorylating Tyr15 remained soluble after ultracentrifugation of interphase extracts whereas a second activity capable of phosphorylating both Thr14 and Tyr15 pelleted. The pelleted fraction contained activities that were detergent extractable and that phosphorylated p $34^{\text {cdc2 }}$ on both Thr14 and Tyr15. The Thr14- and Tyr15-specific kinase activities co-purified through three successive chromatographic steps indicating the presence of a dual-specificity protein kinase capable of acting on $\mathrm{p} 34^{\mathrm{cdc} 2}$.

\section{INTRODUCTION}

In proliferating cells, the phosphorylation state of $\mathrm{p} 34^{\mathrm{cdc} 2}$ changes in a cell cycle-dependent manner. p34 ${ }^{\text {cdc2 } 2}$ is progressively phosphorylated on tyrosine (Tyr15) and threonine (Thr14 and Thr161) residues beginning in S phase and peaking in late $\mathrm{G} 2$ phase (Draetta and Beach,

$\S$ Present addresses: Howard Hughes Medical Institute and Department of Cell Biology and Physiology, Washington University Medical School, Campus Box 8228, 600 S. Euclid Ave., St. Louis, MO 63110-1093; and \|Queensland Institute of Medical Research, Bancroft Centre, 300 Herson Rd., Brisbane, Queensland 4029, Australia ICorresponding author
1988; Draetta et al., 1988; Morla et al., 1989; Krek and Nigg, 1991). Phosphorylation of $\mathrm{p} 34^{\mathrm{cdc} 2}$ on tyrosine and threonine residues occurs in a cyclin-dependent manner (Solomon et al., 1990; Meijer et al., 1991; Parker et al., 1991; Solomon et al., 1992; Atherton-Fessler et al., 1993). At the G2/M phase transition, $\mathrm{p} 34^{\mathrm{cdc} 2}$ is dephosphorylated on tyrosine 15 and threonine 14, but not on threonine 161 (Draetta et al., 1988; Dunphy and Newport, 1989; Gautier et al., 1989; Morla et al., 1989; Solomon et al., 1990; Krek and Nigg, 1991; Norbury et al., 1991). It is the abrupt dephosphorylation of Tyr15 and Thr14 that leads to activation of the p34 ${ }^{\text {cdc2 }}$ kinase and entry of cells into mitosis (Dunphy and Newport, 
1989; Gautier et al., 1989; Morla et al., 1989; Solomon et al., 1990; Krek et al., 1991; Norbury et al., 1991). Following the degradation of cyclin B and exit of cells from mitosis, Thr161 is dephosphorylated during early $\mathrm{G} 1$ (Lorca, 1992). Thus it is clear that $\mathrm{p} 34^{\text {cdc2 }}$ is phosphorylated and dephosphorylated at specific points in the cell cycle, but it is less clear what determines the timing of these phosphorylation and dephosphorylation events.

In Schizosaccharomyces pombe, the phosphorylation of Tyr15 is regulated by protein kinases encoded by wee $1^{+}$and $m i k 1^{+}$(Russell and Nurse, 1987; Lundgren et al., 1991). wee $1^{+}$encodes a $107 \mathrm{kDa}$ protein kinase that directly phosphorylates $\mathrm{p} 34^{\mathrm{cdc} 2}$ on Tyr15 (Featherstone et al., 1991; Parker et al., 1991, 1992), while $m i k 1^{+}$encodes a putative protein kinase that is also involved in maintaining $\mathrm{p} 34^{\text {cdc2 }}$ in its tyrosine phosphorylated and inactive state (Lundgren et al., 1991). Another mitotic control gene identified in $S$. pombe, $c d c 25^{+}$, encodes a mitotic inducer and $\mathrm{p} 34^{\text {cdc2 }}$ activator, which directly dephosphorylates $\mathrm{p} 34^{\text {cdc2 }}$ on Tyr15 (Russell and Nurse, 1986; Millar et al., 1991a). The protein-tyrosine phosphatase encoded by $\mathrm{pyp}^{+}$can functionally substitute for $c d c 25^{+}$in the dephosphorylation of p34 ${ }^{\mathrm{cdc} 2}$ on Tyr15 (Millar et al., 1992). Functional homologs of $c d c 25^{+}$have been identified in a variety of species and have been shown to encode phosphatases capable of dephosphorylating $\mathrm{p} 34^{\mathrm{cdc} 2}$ on Tyr15, as well as Thr14 (Dunphy et al., 1991; Gautier et al., 1991; Strausfeld et al., 1991; Lee et al., 1992; Sebastian et al., 1993).

A human homolog of wee $1^{+}$was cloned based on its ability to complement $w e e 1^{+}$mutants of $S$. pombe (Igarashi et al., 1991). Given that S. pombe $w e e 1^{+}$encodes a protein kinase capable of phosphorylating serine, threonine, and tyrosine residues in vitro, the possibility arose that $w e e 1^{+}$from higher eukaryotes might encode a true dual-specificity kinase that would phosphorylate p34 $4^{\text {cdc2 }}$ on both Tyr15 and Thr14. However, the human homolog of wee ${ }^{+}$was shown to encode a tyrosine-specific protein kinase that phosphorylates $\mathrm{p} 34^{\mathrm{cdc} 2}$ only on Tyr15 in vitro (Honda et al., 1992; Parker and PiwnicaWorms, 1992; McGowen and Russell, 1993). Thus a second inhibitory kinase must exist in higher eukaryotes that is responsible for phosphorylating p $34^{\text {cdc2 }}$ on Thr14. At this time, it is unknown whether this kinase is a serine/threonine-specific kinase that phosphorylates p34 $4^{\text {cdc2 }}$ only on Thr14, or whether it might in fact be a dual-specificity kinase capable of phosphorylating both Thr14 and Tyr15.

The phosphorylation of $\mathrm{p} 34^{\mathrm{cdc} 2}$ on Thr14, Tyr15, and Thr161 during $S$ and G2 parallels the synthesis and accumulation of cyclin $B$, a finding which reinforces the model that cyclin binding potentiates phosphorylation of $\mathrm{p} 34^{\mathrm{cdc} 2}$. Thus the timing of phosphorylation of $\mathrm{p} 34^{\mathrm{cdc} 2}$ is limited to some extent by the synthesis of its regulatory subunit, cyclin B. Regulation of the kinases (i.e., Wee1 and Mik1) and phosphatases (i.e., Cdc25), which act directly on $\mathrm{p} 34^{\mathrm{cdc} 2}$ represents another potential means by which the timing of critical phosphorylation/dephosphorylation events is determined.

In S. pombe and Drosophila, both the mRNA and protein levels of Cdc25 oscillate during the cell cycle, peaking at mitosis (Edgar and O'Farrell, 1989; Ducommun et al., 1990; Edgar and O'Farrell, 1990; Moreno et al., 1990). Thus in these organisms the synthesis of Cdc25 mRNA and protein determines the timing of dephosphorylation and activation of $\mathrm{p} 34^{\mathrm{cdc} 2}$. In Xenopus and humans, however, the abundance of $\mathrm{Cdc} 25$ remains constant throughout the cell cycle (Millar et al., 1991b; Izumi et al., 1992; Jessus and Beach, 1992; Kumagai and Dunphy, 1992). Cdc25 has been shown to physically associate with cyclin B in both Xenopus and human cells (Galaktionov and Beach, 1991; Jessus et al., 1992), and this association may be required for the efficient dephosphorylation of $\mathrm{p} 34^{\mathrm{cdc} 2}$ (Zheng and Ruderman, 1993). Thus dephosphorylation of $\mathrm{p} 34^{\mathrm{cdc} 2}$ by Cdc25 may also be regulated by the formation of the $\mathrm{p} 34^{\mathrm{cdc} 2} /$ cyclin B complex. In addition, Cdc 25 is phosphorylated in a cell cycle dependent manner, with maximal phosphorylation occurring during M phase (Izumi et al., 1992; Kumagai and Dunphy, 1992; Hoffmann et al., 1993). The phosphorylation of Cdc25 is associated with an increase in its phosphatase activity, which is reversible by dephosphorylation in vitro (Izumi et al., 1992; Kumagai et al., 1992; Hoffmann et al., 1993).

Fission yeast $\mathrm{p} 107^{\text {weel }}$ is negatively regulated by the cdr1/nim1 protein kinase, which phosphorylates p107wee1 within its catalytic domain (Coleman et al., 1993; Parker et al., 1993; Wu and Russell, 1993). Recent evidence from Tang et al. (1993) suggests that when fission yeast $\mathrm{p} 107^{\text {weel }}$ (overproduced in insect cells) is mixed with $M$ phase Xenopus egg extracts, its kinase activity is inhibited, and this inhibition is due to phosphorylation of its amino-terminal end (on sites distinct from those phosphorylated by the $\operatorname{cdr} 1 / \mathrm{nim} 1 \mathrm{ki}$ nase)(Tang et al., 1993). These results corroborate an earlier report by Smythe and Newport (1992), which showed that $\mathrm{M}$ phase Xenopus egg extracts possessed diminished $\mathrm{p} 34^{\mathrm{cdc2}}$-specific tyrosine kinase activity when compared with $S$ phase extracts (Smythe and Newport, 1992). It has not been determined whether similar mechanisms of regulation hold true for mammalian cells. Further, these studies have been limited to the regulation of phosphorylation of $\mathrm{p} 34^{\mathrm{cdc} 2}$ at Tyr15. Virtually nothing is known about the regulation of the kinase responsible for the phosphorylation of $\mathrm{p} 34^{\mathrm{cdc} 2}$ on Thr14.

We have developed an assay system where the regulation of the kinases responsible for phosphorylating p34 ${ }^{\text {cdc2 }}$ on Thr14 and Tyr15 can be studied in vitro. We report that the Thr14- and Tyr15-specific kinase activities are coordinately regulated in a cell cycle-dependent manner in both HeLa cells and in extracts prepared from Xenopus eggs. In addition, we have used this assay sys- 
tem to begin to purify the Thr14- and Tyr15-specific kinases from interphase extracts prepared from Xenopus eggs.

\section{MATERIALS AND METHODS}

All procedures relating to Sf9 insect cell culture, generation of recombinant baculovirus, and propagation of recombinant baculovirus were performed as described elsewhere (Piwnica-Worms, 1990). Recombinant viruses encoding $\mathrm{p} 34^{\mathrm{ddc} 2}$ (Arg 33) and p34 $4^{\text {ddc2 }}$ (Phe 15) have been described previously (Parker et al., 1991; Atherton-Fessler et al., 1993).

\section{Mutagenesis of cdc2}

Site-directed mutagenesis of the human cdc2 gene was performed as previously described (Parker et al., 1991; Atherton-Fessler et al., 1993). Single-stranded pSAF20 containing a 679-bp BamHI-HincII N-terminal fragment of cdc2 served as the template for mutagenesis of threonine 14 to alanine (p34 ${ }^{\mathrm{dc} 2}$ [Ala 14]), as well as threonine 14 and tyrosine 15 to alanine and phenylalanine, respectively (p34 ${ }^{\text {odc2 }}$ [Ala14/Phe15]). The oligonucleotides used in these cases were as follows:

5'-GGAGAAGGTGCCTATGGAGTTGTG-3' (Thr14 to Ala14) and 5'AGAAGGTGCCTTTGGAGTTGTGTA-3' (Thr14/Tyr15 to Ala14/ Phe15).

The wild-type cdc2 N-terminus of pSAF10 was then replaced with the mutant $\mathrm{N}$-termini to generate full-length cdc2(Ala14) and cdc2(Ala14/Phe15). Mutations were confirmed by dideoxynucleotide sequencing and a $1.2 \mathrm{~kb} \mathrm{BamHI}$ to EcoRI fragment encoding each mutant was cloned into pVL1393 for the generation of recombinant baculoviruses as described (Piwnica-Worms, 1990).

\section{Labeling of Sf9 Cells In Vivo}

Insect cells infected with recombinant baculovirus were rinsed once with methionine-free Graces medium and then resuspended in methionine-free medium supplemented with $2 \mathrm{mM}$ glutamine, $1.5 \%$ dialyzed calf serum, and $0.30-0.35 \mathrm{mCi} / \mathrm{ml}^{35} \mathrm{~S}$-Express protein label (NEN/DuPont); $\sim 1.5 \times 10^{7}$ cells $/ \mathrm{ml}$. Cells were rocked at room temperature $\left(25^{\circ} \mathrm{C}\right)$ for $3-4 \mathrm{~h}$., then rinsed once in phosphate-buffered saline and stored as cell pellets at $-80^{\circ} \mathrm{C}$.

\section{Preparation of Insect Cell Lysates}

Insect cells were lysed in Nonidet P-40 (NP-40)/tris (hydroxymethyl) aminomethane (Tris) buffer [ $50 \mathrm{mM}$ Tris ( $\mathrm{pH} 7.4$ ), $0.25 \mathrm{M} \mathrm{NaCl}, 50$ $\mathrm{mM} \mathrm{NaF}, 10 \mathrm{mM}$ sodium pyrophosphate ( $\mathrm{NaPPi}), 0.1 \% \mathrm{NP} 40,10 \%$ glycerol] supplemented with $1 \mathrm{mM}$ sodium orthovanadate, $0.15 \mathrm{U} /$ $\mathrm{ml}$ of aprotinin, $20 \mu \mathrm{M}$ pepstatin, and $20 \mu \mathrm{M}$ leupeptin. Cell lysates were clarified at $10000 \times g$ for $15 \mathrm{~min}$.

\section{HeLa Cell Culture and Synchronization}

HeLa cells were cultured in Dulbecco's modified Eagle's medium (DMEM) (GIBCO, Grand Island, NY) with $10 \%$ calf serum (Sigma, St. Louis, MO). The double thymidine block release was performed essentially as described for the thymidine/aphidicolin double block release (Motokura et al., 1991). Briefly, HeLa cells were grown to confluence, then incubated $16 \mathrm{~h}$ with $2 \mathrm{mM}$ thymidine (Sigma). The cells were washed twice with Hank's balanced salt solution and trypsinized off the plates. Collected cells were then reseeded at $\sim 4 \times 10^{6}$ cells per $100 \mathrm{~mm}$ tissue culture dish in DMEM/10\% calf serum supplemented with $24 \mu \mathrm{M}$ each of thymidine and deoxycytidine (Sigma) and incubated for $8 \mathrm{~h}$. Cells were then incubated for a further $16 \mathrm{~h}$ in the presence of $2 \mathrm{mM}$ thymidine. The plates were washed three times with prewarmed $\left(37^{\circ} \mathrm{C}\right)$ DMEM and cultured in DMEM $/ 10 \%$ calf serum for 0 to $14 \mathrm{~h}$, as indicated in the appropriate figure legends (Figures 3 and 4). At the indicated times, plates were washed with ice cold phosphate-buffered saline (PBS), and stored at $-80^{\circ} \mathrm{C}$ until use. Nocodazole arrested cells were obtained by incubating cells in the presence of $0.1 \mu \mathrm{g} / \mathrm{ml}$ nocodazole (Sigma) for 10 to $18 \mathrm{~h}$. Mitotic cells were then collected by mitotic shake off. Cells were delayed in G2 by the addition of $7.5 \mu \mathrm{g} / \mathrm{ml}$ Hoechst 33342 (Calbiochem, San Diego, CA) $4 \mathrm{~h}$ after release from a double thymidine block (Crissman et al., 1990). Plates were frozen at $-80^{\circ} \mathrm{C}$ until needed. Immunoprecipitation assays (histone $\mathrm{H} 1$ kinase assays) or phosphorylation (shift) assays were performed as described below. For histone $\mathrm{H} 1$ kinase assays, HeLa cells were lysed in modified NETN buffer $(20 \mathrm{mM}$ Tris pH 8.0, 1 mM EDTA, $0.5 \%$ NP-40, $0.4 \mathrm{M} \mathrm{NaCl}, 10 \mathrm{mM} \mathrm{NaF}, 0.1 \mathrm{mM}$ sodium vanadate, $2 \mathrm{mM}$ dithiothreitol (DTT) and $5 \mu \mathrm{M}$ microcystin (Gibco-BRL). For the Thr14/Tyr15 phosphorylation (shift) assays, HeLa cells were lysed in buffer consisting of $50 \mathrm{mM}$ Tris $\mathrm{pH} 7.5,5$ mM EDTA, $2 \mathrm{mM}$ DTT, $10 \mathrm{mM} \mathrm{NaF}, 0.1 \mathrm{mM}$ sodium vanadate, 250 $\mathrm{mM} \mathrm{NaCl}$ and $0.1 \%$ Brij- 35 .

\section{Histone H1 Kinase Assays (HeLa Cells)}

Approximately $4 \times 10^{6} \mathrm{HeLa}$ cells (at different points in the cell cycle) were lysed in $1 \mathrm{ml}$ of a modified NETN buffer (as described above). Anti-cyclin B serum $(2.0 \mu \mathrm{l})$ (Atherton-Fessler et al., 1993) was added to $50 \mu \mathrm{l}$ of lysate, the reaction was brought up to $300 \mu \mathrm{l}$ with NETN buffer [ $20 \mathrm{mM}$ Tris (pH 8.0), $100 \mathrm{mM} \mathrm{NaCl}, 1 \mathrm{mM}$ EDTA, $0.5 \%$ NP40] containing $1 \mathrm{mM}$ sodium orthovanadate, $0.15 \mathrm{U} / \mathrm{ml}$ of aprotinin, $20 \mu \mathrm{M}$ pepstatin, and $20 \mu \mathrm{M}$ leupeptin. Reactions were incubated for $2 \mathrm{~h}$ at $4^{\circ} \mathrm{C}$. Twenty microliters of $50 \%$ slurry of Sepharose CL-4B protein $A$ beads were added, and the immunoprecipitation was continued for $1 \mathrm{~h}$ at $4^{\circ} \mathrm{C}$. Immunoprecipitates were washed twice in NETN, twice in NETN containing $1 \mathrm{mM} \mathrm{NaCl}$, and twice in incomplete kinase buffer ( $50 \mathrm{mM}$ Tris pH 7.4, $10 \mathrm{mM} \mathrm{MgCl}_{2}, 5 \mathrm{mM}$ DTT). Forty microliters of complete kinase buffer [50 mM Tris (pH 7.4), $10 \mathrm{mM}$ $\mathrm{MgCl}_{2}, 5 \mathrm{mM}$ dithiothreitol, $0.4 \mu \mathrm{g} / \mathrm{ml}$ histone $\mathrm{H1}, 10 \mu \mathrm{M}$ ATP and 0.5 to $1.0 \mathrm{mCi} / \mathrm{ml} \gamma^{32} \mathrm{P}$-labeled ATP] was added to the washed immunoprecipitates and reactions were incubated at $30^{\circ} \mathrm{C}$ for $10 \mathrm{~min}$. Reactions were terminated by the addition of sodium dodecyl sulfate (SDS)-sample buffer, and the reaction products were resolved by SDSpolyacrylamide gel electrophoresis (PAGE). Phosphorylation of histone $\mathrm{H} 1$ was detected by autoradiography and quantitated by Cherenkov counting in a liquid scintillation counter.

\section{Thr14/Tyr15 Phosphorylation (Shift) Assays (HeLa Cells)}

Lysates were prepared from insect cells infected with recombinant viruses encoding $\mathrm{p} 34^{\mathrm{edc} 2}$ (either wild-type or mutant forms) and labeled in vivo with ${ }^{35} \mathrm{~S}$-methionine. These $\left.{ }^{35} \mathrm{~S}\right) \mathrm{p} 34^{\text {odc2 }}$-containing lysates were combined with insect cell lysates containing GST-cyclin B and incubated in the presence of $10 \mathrm{mM} \mathrm{MgCl}_{2}$ and $1 \mathrm{mM}$ ATP for $30 \mathrm{~min}$ at $25^{\circ} \mathrm{C}$ to allow for efficient formation of $\left({ }^{35} \mathrm{~S}\right) \mathrm{p} 34^{\text {cdc2 }} / \mathrm{GST}$-cyclin B complexes. $\left({ }^{35} \mathrm{~S}\right) \mathrm{p} 34^{\mathrm{cdc} 2} / \mathrm{GST}$-cyclin B complexes were precipitated with glutathione agarose, and the precipitates were washed twice with NP-40/Tris buffer, and three times with $Q$ buffer [QB: $20 \mathrm{mM}$ triethanolamine- $\mathrm{HCl}$, (pH 7.6) $50 \mathrm{mM} \mathrm{NaCl}, 2 \mathrm{mM}$ EDTA, $1 \mathrm{mM}$ DTT, 5 $\mathrm{mM}$ sodium fluoride, $1 \mathrm{mM}$ sodium pyrophosphate] containing $0.05 \%$ Brij-35 (SurfactAmps; Pierce, Rockford, IL) prior to use as a substrate for Thr14 and/or Tyr15 phosphorylation in vitro. Approximately 1 to $3 \mu \mathrm{g}$ of $\mathrm{p} 34^{\mathrm{cdc} 2}$ protein was present in each assay. HeLa cell lysates were added to $\left({ }^{35} \mathrm{~S}\right) \mathrm{p} 34^{\text {edc2 }} / \mathrm{GST}$-cyclin B complexes, and phosphorylation reactions were initiated by the addition of $1 / 10$ volume of reaction mixture consisting of $\mathrm{QB}(+0.05 \%$ Brij-35) supplemented with $100 \mathrm{mM} \mathrm{MgCl} 2,10 \mathrm{mM}$ sodium orthovanadate, and $20 \mathrm{mM}$ ATP (final concentrations $10 \mathrm{mM} \mathrm{MgCl}, 1 \mathrm{mM}$ sodium orthovanadate, and $2 \mathrm{mM}$ ATP). HeLa cell lysates were normalized for total cell protein for Figure 3 (1.0 mg per condition). In Figure 4, several tissue culture dishes were seeded with $\sim 4 \times 10^{6} \mathrm{~S}$-phase arrested cells (after the double thymidine block), and one plate was harvested for each shift assay. Protein concentrations ranged from 1.0 to $2.0 \mathrm{mg}$ throughout the course of the experiment. We typically measured a 
15 to $20 \%$ increase in total cellular protein from cells harvested early in the time course ( $\mathrm{S}$ and $\mathrm{G} 2$ ) as compared with those harvested later (M and early G1). Typical reaction volumes ranged from $0.5-1.0 \mathrm{ml}$ depending on the protein concentration of HeLa lysates. Reactions were allowed to proceed at $25^{\circ} \mathrm{C}$ for $30-45 \mathrm{~min}$., after which the $\left({ }^{35} \mathrm{~S}\right) \mathrm{p} 34^{\text {cdc2 }} / \mathrm{GST}$-cyclin B precipitates were washed twice with $0.5 \mathrm{M}$ $\mathrm{LiCl}$ in $20 \mathrm{mM}$ Tris $\mathrm{pH}$ 8.0. Precipitates were solubilized in SDSsample buffer and boiled for 3-5 min. Proteins were resolved by SDSPAGE (12\% acrylamide gels) and visualized by Coomassie blue staining. $\left.{ }^{35} \mathrm{~S}\right) \mathrm{p} 34^{\text {cdc2 }}$ was visualized and quantitated by autoradiography or PhosphorImage scanning.

\section{Xenopus Egg Extracts}

The following buffers were used routinely in the preparation of extracts from Xenopus eggs: XB [10 mM N-2-hydroxyethylpiperazine- $N$ '-2ethanesulfonic acid (HEPES), pH 7.7, $100 \mathrm{mM} \mathrm{KCl}, 0.1 \mathrm{mM} \mathrm{CaCl}{ }_{2}$, $1 \mathrm{mM} \mathrm{MgCl}$, and $50 \mathrm{mM}$ sucrose), MMR (5 mM HEPES, $\mathrm{pH} 7.8$, $100 \mathrm{mM} \mathrm{NaCl}, 2 \mathrm{mM} \mathrm{KCl}, 1 \mathrm{mM} \mathrm{MgCl} 2,2 \mathrm{mM} \mathrm{CaCl}_{2}$, and $0.1 \mathrm{mM}$ EDTA). Xenopus egg extracts were prepared essentially as described (Murray and Kirschner, 1989), with minor modifications. Briefly, to prepare CSF-arrested (M-phase) extracts, Xenopus eggs were dejellied in $2 \%$ cysteine, $\mathrm{pH} 7.8$, and transferred into $\mathrm{XB}$ containing $5 \mathrm{mM}$ EGTA, $10 \mu \mathrm{g} / \mathrm{ul}$ of pepstatin A and chymostatin, and $100 \mu \mathrm{g} / \mathrm{ul}$ of cytochalasin B. Eggs were centrifuged for $3 \mathrm{~min}$ at $400 \times g$ to remove excess buffer. Packed eggs were then crushed by centrifugation for $10 \mathrm{~min}$ at $10000 \times g$ in a swinging bucket rotor. The cytoplasmic layer was removed, placed on ice, and pepstatin A, chymostatin, and cytochalasin B were added to $10 \mu \mathrm{g} / \mathrm{ul}$ each. Extracts were then centrifuged for $15 \mathrm{~min}$ at $15000 \times g\left(4^{\circ} \mathrm{C}\right)$, followed by $15 \mathrm{~min}$ at 10000 $\times g\left(4^{\circ} \mathrm{C}\right)$ to clarify. Interphase extracts were derived from CSF-arrested extracts by the addition of $100 \mu \mathrm{g} / \mathrm{ml}$ cycloheximide and $0.4 \mathrm{mM}$ $\mathrm{CaCl}_{2}$ and incubation for $40 \mathrm{~min}$ at $23^{\circ} \mathrm{C}$. Alternatively, interphase extracts were obtained by activation of dejellied eggs with calcium ionophore. In this case, dejellied eggs were washed with $0.2 X \mathrm{MMR}$, and then activated in a minimal volume of $0.2 \mathrm{X}$ MMR containing 5 $\mu \mathrm{g} / \mathrm{ml} \mathrm{A23187}$ for 60 to $90 \mathrm{~s}$. Eggs were washed extensively with $0.2 \mathrm{X} \mathrm{MMR}$ and incubated for $40 \mathrm{~min}$ at $23^{\circ} \mathrm{C}$ to allow for complete entry into interphase. Extracts were then prepared as described above for CSF-arrested extracts. Finally, extracts were aliquoted, frozen, and stored at $-80^{\circ} \mathrm{C}$ until needed. For time course experiments (Figure $6 \mathrm{~A}), \mathrm{CSF}$-arrested extracts were activated with $0.4 \mathrm{mM} \mathrm{CaCl}_{2}$ in the absence of added protease inhibitors or cycloheximide. Aliquots were removed at the times indicated after activation, quick frozen, and stored at $-80^{\circ} \mathrm{C}$. To monitor exit from $\mathrm{M}$-phase into interphase, $3 \mu \mathrm{l}$ of each extract were removed, diluted 10 -fold in water, and were frozen at $-80^{\circ} \mathrm{C}$ for histone $\mathrm{H} 1$ kinase assays. Histone $\mathrm{H} 1$ assays were performed for $10 \mathrm{~min}$ at $30^{\circ} \mathrm{C}$ in a final volume of $30 \mu$ l. Reactions consisted of $5 \mu$ l of diluted extract, $20 \mathrm{mM}$ HEPES (pH 7.5), $5 \mathrm{mM}$ EGTA, $15 \mathrm{mM} \mathrm{MgCl}, 1 \mathrm{mM}$ DTT, $200 \mu \mathrm{M}$ ATP, $10 \mu \mathrm{g}$ of histone $\mathrm{H} 1,10 \mu \mathrm{Ci} \gamma^{32} \mathrm{P}$ ATP, and $0.2 \mu \mathrm{g}$ of protein kinase A inhibitor. The interphase extracts used in figure $6, \mathrm{~B}$ and $\mathrm{C}$ were a gift from Dr. Peter Jackson (Dept. Cell Biology, Harvard Medical School) and were prepared as described by Murray (1991). To two $50 \mu$ l aliquots of interphase extract $(\sim 2 \mathrm{mg}$ each) the following was added: $2.5 \mu \mathrm{l}$ of a $20 X$ energy mix ( $150 \mathrm{mM}$ phosphocreatine, $20 \mathrm{mM}$ ATP, $2 \mathrm{mM}$ EGTA, $20 \mathrm{mM} \mathrm{MgCl}$ ) and $5 \mu \mathrm{l}$ of $10 \mathrm{X}$ protease inhibitor mix $(0.1$ $\mathrm{mg} / \mathrm{ml}$ each pepstatin A, chymostatin, and leupeptin). The interphase extract was either incubated alone or in the presence of $2 \mu \mathrm{l}$ (14 to 20 $\mu \mathrm{g}$ ) of $\Delta 90 \mathrm{cyclin}$ (Glotzer et al., 1991) at $23^{\circ} \mathrm{C}$ for $50 \mathrm{~min}$ to generate a stable mitotic extract. Three milliliters of each extract were removed for histone $\mathrm{H} 1$ kinase assays as described above. The remainder of each extract was diluted with $350 \mu \mathrm{l}$ of QB containing $0.5 \%$ Brij- 35 , and $100 \mu \mathrm{l}$ aliquots were used in shift assays by incubating with $\left({ }^{35} \mathrm{~S}\right)$ p $34^{\text {cdc2 }} /$ GST-cyclin B precipitates for various periods of time as described below.

\section{Thr14/Tyr15 Phosphorylation (Shift) Assays (Xenopus Egg Extracts)}

$\left({ }^{35} \mathrm{~S}\right) \mathrm{p} 34^{\text {ddc2 }} / \mathrm{GST}$-cyclin B complexes were prepared as described above and washed with QB (+Brij-35). Xenopus egg extracts (1-2 mg total protein) or samples from selected column fractions were added to $\left({ }^{35} \mathrm{~S}\right) \mathrm{p} 34^{\mathrm{cdc} 2} / \mathrm{GST}$-cyclin B complexes and phosphorylation reactions were initiated by the addition of $1 / 10$ volume of reaction mixture consisting of $\mathrm{QB}(+\mathrm{Brij}-35)$ supplemented with $100 \mathrm{mM} \mathrm{MgCl}, 10$ $\mathrm{mM}$ sodium orthovanadate, and $20 \mathrm{mM}$ ATP (final concentrations 10 $\mathrm{mM} \mathrm{MgCl} 2,1 \mathrm{mM}$ sodium orthovanadate, and $2 \mathrm{mM} \mathrm{ATP})$. For the shift assay shown in Figure 6B, reactions were adjusted to $1 \mu \mathrm{M} \mathrm{mi-}$ crocystin. Typical reaction volumes ranged from 0.05 to $1.5 \mathrm{ml}$ depending on the protein concentration of samples to be assayed. Reactions were allowed to proceed at $25^{\circ} \mathrm{C}$ for $30-45 \mathrm{~min}$ after which the $\left({ }^{35} \mathrm{~S}\right) \mathrm{p} 34^{\text {cdc2 }} / \mathrm{GST}$-cyclin B precipitates were washed twice with $0.5 \mathrm{M} \mathrm{LiCl}$ in $20 \mathrm{mM}$ Tris $\mathrm{pH}$ 8.0. Precipitates were solubilized in SDS-sample buffer and boiled for 3-5 min. Proteins were resolved by SDS-PAGE (12\% acrylamide gels) and visualized by Coomassie blue staining. $\left({ }^{35} \mathrm{~S}\right) \mathrm{p} 34^{\text {cdc2 }}$ was visualized by autoradiography or PhosphorImage scanning.

\section{Separation of Two Activities in Xenopus Egg Extracts Capable of Phosphorylating $p 34^{\text {cdc2 }}$ on Thr14/Tyr15}

Eggs were collected and washed in $0.1 \mathrm{M} \mathrm{NaCl}$. Interphase extract prepared as described above, was diluted two- to four-fold with buffer A (20 mM HEPES pH 7.6, 10\% glycerol, 1 mM EDTA, $5 \mathrm{mM} \mathrm{NaF}, 1$ $\mathrm{mM}$ sodium pyrophosphate) containing $50 \mathrm{mM} \mathrm{NaCl}, 1 \mathrm{mM}$ DTT, $0.1 \mathrm{U} / \mathrm{ml}$ aprotinin, $10 \mu \mathrm{M}$ pepstatin, and $10 \mu \mathrm{M}$ leupeptin and was centrifuged at $150000 \times g$ for $20 \mathrm{~min}$ at $4^{\circ} \mathrm{C}$. The supernatant was saved and referred to as $150 \mathrm{~S}$. The pellet (150P) was solubilized in buffer A containing $0.05 \%$ Brij-35 (Pierce) and placed on ice for 20 min prior to recentrifugation at $150000 \times g$. The pellet from the second centrifugation was further extracted with buffer A containing 0.2 and $0.5 \%$ of Brij-35 as described above. Alternatively, the 150000 $\times \&$ pellet was extracted with buffer A containing 0.1 and $0.5 \%$ Triton $X-100$.

To purify Thr14 kinase activity from Xenopus extract, the 150000 $\times \&$ pellet was washed in buffer $\mathrm{A}$ containing $0.5 \mathrm{M} \mathrm{NaCl}$ and protease inhibitors, centrifuged at $150000 \times g$ for $20 \mathrm{~min}$, and resolubilized in buffer A containing $0.5 \%$ Brij-35. The tube was placed on ice for $20 \mathrm{~min}$ and recentrifuged at $150000 \times g$. The supernatant (150P0.5B) was saved and further fractionated by column chromatography (see below).

\section{Phosphatase Assays}

To characterize the nature of kinase(s) in both the $150000 \times g$ supernatant and the pellet, $\left({ }^{35} \mathrm{~S}\right)$-p $34^{\text {cdc2 }} /$ GST-Cyclin B was precipitated with glutathione agarose beads and incubated with either 150000 $\times g$ supernatant or pellet solubilized with $0.5 \%$ Brij- 35 under kinase conditions as described above. The reactions were stopped by washing the beads two times with gel shift buffer $[50 \mathrm{mM}$ Tris ( $\mathrm{pH} 7.4), 50$ $\mathrm{mM} \mathrm{NaCl}, 2 \mathrm{mM}$ EDTA, $1 \mathrm{mM}$ DTT, $5 \mathrm{mM}$ sodium fluoride, $1 \mathrm{mM}$ sodium pyrophosphate containing $0.05 \%$ Brij-35] and three times with phosphatase buffer ( $50 \mathrm{mM}$ Tris $\mathrm{pH}$ 7.4, 2 mM EDTA, $2 \mathrm{mM}$ DTT). The beads were then resuspended in $400 \mu \mathrm{l}$ of phosphatase buffer and incubated in the presence or absence of $1 \mu \mathrm{g}$ of yeast PTP1 phosphatase at $25^{\circ} \mathrm{C}$ for $30 \mathrm{~min}$. The reactions were then washed with $0.5 \mathrm{M} \mathrm{LiCl}$ and analyzed on a $12 \%$ SDS-PAGE.

\section{Fractionation of Xenopus Egg Extracts}

The Thr14/Tyr15 kinase activities were solubilized from the 150000 $\times g$ pellet by extraction with buffer $\mathrm{A} / 0.5 \%$ Brij- 35 as described above ( $\sim 40$-fold purification). A total of $36 \mathrm{ml}$ of $150 \mathrm{P0}$.5B fraction was loaded onto a $12 \mathrm{ml}$ Q-Sepharose (Pharmacia, Piscataway, NJ) column equilibrated with buffer $A B$ [ 20 mM HEPES ( $\mathrm{pH} 7.6$ ), 10\% glycerol, $1 \mathrm{mM}$ EDTA, $5 \mathrm{mM} \mathrm{NaF}, 1 \mathrm{mM}$ sodium pyrophosphate, $0.05 \%$ Brij35] containing $50 \mathrm{mM} \mathrm{NaCl}$ at a flow rate of $0.5 \mathrm{ml} / \mathrm{min}$. Proteins bound to the column were eluted with a $100 \mathrm{ml} \mathrm{NaCl}$ gradient from $0.05 \mathrm{M}$ to $1 \mathrm{M}$ in buffer $\mathrm{AB}$ at $1 \mathrm{ml} / \mathrm{min}$. Three milliliter fractions 
were collected and assayed for the ability to retard the electrophoretic mobility of $\left({ }^{35} \mathrm{~S}\right)$ - $\mathrm{p} 34^{\text {cdc2 }}$ in the phosphorylation assay described above ( 3.6-fold purification). The active fractions (eluted at 220 to 450 $\mathrm{mM} \mathrm{NaCl}$ ) were pooled and desalted on a Sephadex G-25 column in buffer $A B$ and then applied to a $7 \mathrm{ml} \mathrm{S}$-Sepharose (Pharmacia) column at a flow rate of $0.5 \mathrm{ml} / \mathrm{min}$. Bound proteins were eluted from the column with buffer $\mathrm{AB}$ containing $0.3 \mathrm{M} \mathrm{NaCl}$ (S0.3) ( $\sim 6.5$-fold purification). The S0.3 fraction was desalted in buffer $A B$ to $24 \mathrm{ml}$ in total volume, and $2 \mathrm{ml}$ of desalted S0.3 were applied to a $1 \mathrm{ml}$ Reactive Yellow 3 column (Sigma) equilibrated with buffer $A B$ at $0.3 \mathrm{ml} / \mathrm{min}$. Bound proteins were eluted with a $15 \mathrm{ml}$ gradient of 0 to $1 \mathrm{M} \mathrm{NaCl}$ in buffer $A B$, and $1 \mathrm{ml}$ fractions were collected and assayed for the ability to retard the electrophoretic mobility of $\left({ }^{35} \mathrm{~S}\right)-\mathrm{p} 34^{\text {cdc2 }}$ ( 3-fold purification). The overall purification of the kinase activity was estimated to be $\sim 2800$-fold.

\section{RESULTS}

\section{An In Vitro Assay for Thr14- and Tyr15-Specific Kinase Activities}

Human $\mathrm{p} 34^{\mathrm{cdc} 2}$ has been demonstrated to decrease in electrophoretic mobility upon phosphorylation of either Thr14 or Tyr15 residues, with a further decrease in mobility upon phosphorylation of both Thr14 and Tyr15 (Solomon et al., 1992). Thus changes in the electrophoretic mobility of p34 ${ }^{\text {cdc2 }}$ can be used as a measure of changes in its state of phosphorylation at Thr14 and Tyr15. Phosphorylation of Thr161 does not result in a detectable change in the electrophoretic mobility of p34 ${ }^{\text {cdc2 }}$. We took advantage of this fact to develop an assay that monitors the activities of Thr14- and Tyr15specific kinases in HeLa cell lysates. To obtain a substrate for these kinases, insect cells overproducing p34 $4^{\text {cdc2 }}$ (either wild-type or mutant forms) were labeled with ${ }^{35} \mathrm{~S}$-methionine in vivo. Lysates prepared from these ${ }^{35} \mathrm{~S}$-labeled cells were then combined with lysates from insect cells producing cyclin B fused with the glutathioneS-transferase protein, GST-cyclin B, and the resulting p34 ${ }^{\text {cdc2 }} /$ GST-cyclin B complexes were isolated using glutathione agarose chromatography. By forming $\mathrm{p} 34^{\mathrm{cdc}} /$ GST-cyclin B complexes in vitro, we could obtain large amounts of protein substrate in which only the $\mathrm{p} 34^{\text {cdc2 }}$ component was radioactively labeled. In addition, isolation of complexes by virtue of the GST-cyclin B fusion protein insures that $100 \%$ of the $\mathrm{p} 34^{\text {cdc2 }}$ isolated is associated with cyclin $B$ and therefore is a preferred substrate for phosphorylation (Solomon et al., 1990; Meijer et al., 1991; Parker et al., 1991, 1992).

The Thr14 and Tyr15 kinase activities of HeLa cells were assayed by mixing HeLa cell lysates with $\left({ }^{35} \mathrm{~S}\right) \mathrm{p} 34^{\text {cdc2 }} / \mathrm{GST}$-cyclin B complexes in the presence of $\mathrm{MgATP}$. Inhibitors of both tyrosine- and serine/threonine-specific protein phosphatases were included in the reactions so that it was possible to specifically monitor the activities of the Thr14/Tyr15 kinases. Phosphorylation of Thr14 and Tyr15 was then assessed by monitoring the electrophoretic mobility of the ${ }^{35} \mathrm{~S}$-labeled p34 ${ }^{\text {cdc2 }}$. As shown in Figure 1, upon incubation with HeLa cell lysate, $\mathrm{p} 34^{\text {cdc2 }}$ shifts from a single elec-

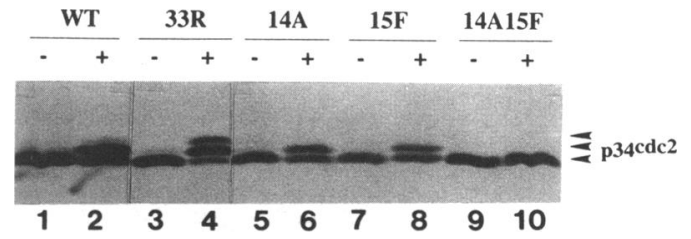

Figure 1. p34 ${ }^{\text {dc2 }}$ is phosphorylated on Thr14 and Tyr15 in HeLa cell lysates. Insect cells producing wild-type $\mathrm{p} 34^{\mathrm{cdc} 2}$ (WT, lanes 1 and 2), p34 ${ }^{\text {dc2 }}$ (Arg33) (33R, lanes 3 and 4), p34 ${ }^{\text {cdc2 }}$ (Ala14) (14A, lanes 5 and 6), p34 $4^{\text {cdc2 }}$ (Phe15) $(15 \mathrm{~F}$, lanes 7 and 8$)$, or $\mathrm{p} 34^{\text {cdc2 }}$ (Ala14Phe15) $(14 \mathrm{~A} 15 \mathrm{~F}$, lanes 9 and 10$)$ were labeled in vivo with ${ }^{35} \mathrm{~S}$-methionine, lysed and combined with lysates from insect cells expressing GSTcyclin B. p34 ${ }^{\text {cdc2 }} /$ GST-cyclin B complexes were precipitated with glutathione agarose beads, and precipitates were incubated for $45 \mathrm{~min}$ at $25^{\circ} \mathrm{C}$ with buffer alone (-, lanes $1,3,5,7$, and 9) or with HeLa cell extract $(+$, lanes $2,4,6,8$, and 10$)$. Proteins were resolved by SDS-PAGE and ${ }^{35}$ S-labeled $\mathrm{p} 34^{\text {odc2 }}$ was visualized by autoradiography.

trophoretic form at $34 \mathrm{kDa}$ (lane 1) to three electrophoretic forms (lane 2) indicative of phosphorylation on either Thr14 and Tyr15. The middle band seen in lane 2 contains $\mathrm{p} 34^{\mathrm{cdc} 2}$, which is phosphorylated on Thr14 or Tyr15, while the topmost band contains $\mathrm{p} 34^{\mathrm{cdc} 2}$ phosphorylated at both sites (see below). A kinase-deficient form of $\mathrm{p} 34^{\mathrm{cdc2}}, \mathrm{p} 34^{\mathrm{cdc}}$ (Arg33) (lanes 3 and 4), underwent a comparable shift in electrophoretic mobility after incubation with HeLa cell lysate (lane 4). To confirm that the observed shift in electrophoretic mobility corresponds to phosphorylation of $\mathrm{p} 34^{\text {cdc2 }}$ at Thr14 and Tyr15, the mobilities of nonphosphorylatable forms of p34 ${ }^{\text {cdc2 }}$ were examined after incubation alone or in the presence of HeLa cell lysate. When Thr14 is changed to Ala to generate $\mathrm{p} 34^{\text {cdc2 }}$ (Ala14) (lanes 5 and 6), p34 $4^{\text {cdc2 }}$ undergoes a single shift in electrophoretic mobility (lane 6) in the presence of HeLa cell lysate, indicative of phosphorylation at Tyr15. Likewise, when Tyr15 is changed to Phe, p34 ${ }^{\text {cdc2 }}$ (Phe15) (lanes 7 and 8), a single shift in mobility is observed (lane 8), indicative of phosphorylation at Thr14. If both Thr14 and Tyr15 are mutated, to Ala and Phe, respectively, the electrophoretic mobility of $\mathrm{p} 34^{\mathrm{cdc} 2}$ is no longer affected by incubation with HeLa cell lysate (lanes 9 and 10). Thus phosphorylation of $\mathrm{p} 34^{\mathrm{cdc} 2}$ at Thr14 and/or Tyr15 can be assessed by monitoring the electrophoretic mobility of $\left({ }^{35} \mathrm{~S}\right) \mathrm{p} 34^{\text {cdc2 }}$ (either wild-type or mutant forms). In addition, these results indicate that phosphorylation of Thr14 and Tyr15 can occur independent of one another.

\section{Dependence of Thr14/Tyr15 Phosphorylation on HeLa Cell Protein Concentration}

As shown in Figure 2 (top panel), with increasing amounts of HeLa cell protein, p34 ${ }^{\text {cdc2 }}$ (Arg33) shifts from a single electrophoretic form at $34 \mathrm{kDa}$ to three electrophoretic forms indicative of phosphorylation at Thr14 and Tyr15. With the addition of $0.5 \mathrm{mg}$ of HeLa cell protein, $\sim 30 \%$ of $\mathrm{p}^{34^{\text {cdc2 }}}$ (Arg33) was phosphorylated on one or both sites (as indicated by a decrease in elec- 


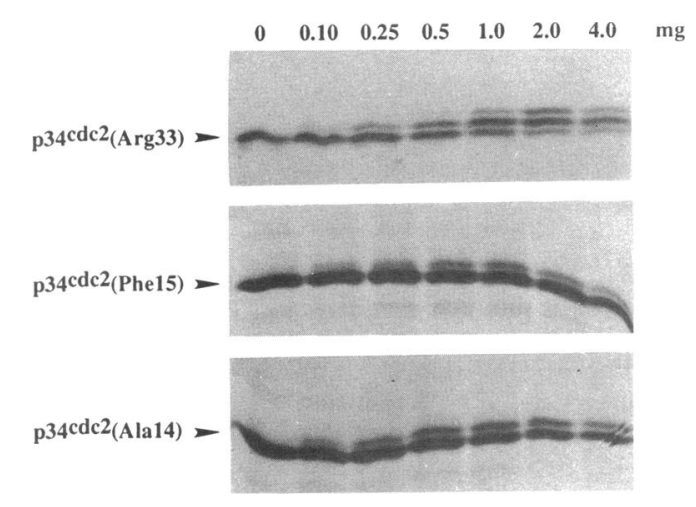

Figure 2. Dependence of Thr14- and Tyr15-specific kinase activities on concentration of $\mathrm{HeLa}$ cell lysates. Protein precipitates containing p34 ${ }^{\text {cdc2 }}$ (Arg33) (top), p34 ${ }^{\text {cdc2 }}$ (Phe15) (middle), or p34 ${ }^{\text {ddc2 }}$ (Ala14) (bottom) in complex with GST-cyclin B were prepared as described in Figure 1. p34 dc2 /GST-cyclin B complexes were incubated for $30 \mathrm{~min}$ at $25^{\circ} \mathrm{C}$ with varying amounts of HeLa cell lysate ( $0-4 \mathrm{mg}$ total protein). Proteins were resolved by SDS-PAGE and ${ }^{35} \mathrm{~S}$-labeled $\mathrm{p} 34^{\text {dc2 } 2}$ was visualized by autoradiography.

trophoretic mobility), and this fraction increased to $>80 \%$ with the addition of $2 \mathrm{mg}$ of HeLa protein. Phosphorylation of $\mathrm{p} 34^{\mathrm{cdc}}$ (Arg33) followed saturation kinetics up to $2 \mathrm{mg}$ of HeLa cell protein. At the highest concentration of HeLa cell protein $(4 \mathrm{mg}$ in this experiment), the $\mathrm{p} 34^{\mathrm{cdc} 2}(\mathrm{Arg} 33) / \mathrm{GST}$-cyclin B substrate began to elute from the glutathione agarose, leading to a slight decrease in detected kinase activity.

To monitor the Thr14 and Tyr15 kinase activities independently, either p34 $4^{\text {cdc2 }}$ (Phe15) or p34 $4^{\text {cdc2 }}$ (Ala14) were assayed with varying amounts of HeLa cell protein. As shown in Figure 2 (middle), when $\mathrm{p} 34^{\mathrm{cdc} 2}$ (Phe15) is incubated with increasing amounts of HeLa cell protein, it becomes progressively phosphorylated on Thr14, as indicated by the appearance of a slower electrophoretic form. Similarly, p34 ${ }^{\text {cdc2 }}$ (Ala14) becomes progressively phosphorylated on Tyr15 with increasing amounts of HeLa cell protein (Figure 2, bottom). These results indicate that the protein concentration dependence of both activities are comparable, with maximal phosphorylation occurring at 1 to $2 \mathrm{mg}$ HeLa protein. Thus, for experiments designed to detect potential differences in the Thr14 and/or Tyr15 kinase activities, an assay of 0.5 to $1 \mathrm{mg}$ of HeLa lysate was judged to be within the linear range of both kinase activities.

\section{Cell Cycle Regulation of Thr14- and Tyr15-Specific Kinase Activities in HeLa Cells}

During a normal cell division cycle, $\mathrm{p} 34^{\mathrm{cdc} 2} /$ cyclin B complexes begin to accumulate during late $S$ phase, and these complexes are maintained in an inactive state by phosphorylation at Thr14 and Tyr15 (Draetta and Beach, 1988; Draetta et al., 1988; Dunphy and Newport, 1989; Gautier et al., 1989; Morla et al., 1989; Solomon et al., 1990; Krek et al., 1991; Norbury et al., 1991). At the transition from G2 to M phase, Thr14 and Tyr15 are rapidly dephosphorylated and $\mathrm{p} 34^{\text {cdc2 }}$ is activated as a protein kinase (Dunphy and Newport, 1989; Gautier et al., 1989; Morla et al., 1989; Solomon et al., 1990; Krek et al., 1991; Norbury et al., 1991). We wished to determine whether the Thr14- and Tyr15-specific kinase activities present in HeLa cells are regulated in a cell cycle dependent manner. In Figure 3, HeLa cells were tested at various stages of the cell cycle for their ability to phosphorylate $\mathrm{p} 34^{\text {cdc2 }}$ at Thr14 and/or Tyr15 using the assay described above. HeLa cells were synchronized in $S$ phase by a double thymidine block and were then released and allowed to proceed through $G 2$ into mitosis $(M)$ or were delayed in $G 2$ with the DNA binding dye, Hoechst 33342 . Lysates prepared from aynchronous HeLa cells were capable of phosphorylating p34 ${ }^{\text {cdc2 }}$ (Arg33) on both Thr14 and Tyr15, resulting in the appearance of two retarded electrophoretic forms (Figure 3, top panel). Interestingly, as shown in Figure 3 (top), lysates prepared from both S phase and G2 phase cells phosphorylated Thr14 and Tyr15 to the same extent as those prepared from asynchronous cells $[\sim 70-$ $80 \%$ of $\mathrm{p}^{\mathrm{cdc}}$ (Arg33) phosphorylated on one or both sites]. However, mitotic cells obtained after release from a double thymidine block possessed significantly less Thr14- and/or Tyr15-specific kinase activity, as judged by a decrease in the proportion of $\mathrm{p} 34^{\mathrm{cdc} 2}(\mathrm{Arg} 33) \mathrm{mi}-$ grating with a retarded electrophoretic mobility $(\sim 35 \%$ phosphorylated; Figure 3, top). If mitotic cells were obtained after a nocodazole arrest, these results were even more striking, in that $\mathrm{p} 34^{\mathrm{cdc} 2}$ (Arg33) was not detectably phosphorylated on either Thr14 or Tyr15 (Figure 3, top) when compared with controls.

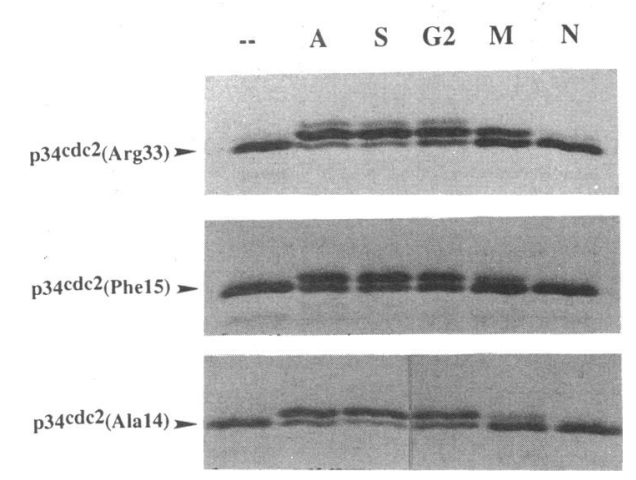

Figure 3. Phosphorylation of $\mathrm{p} 34^{\mathrm{cdc} 2}$ on Thr14 and Tyr15 is diminished in mitotic HeLa cell lysates. Protein precipitates containing p34 ${ }^{\text {ddc2 }}$ (Arg33) (top), p34 ${ }^{\text {cdc2 }}$ (Phe15) (middle), or p34 $4^{\text {ddc2 }}$ (Ala14) (bottom) in complex with GST-cyclin B were prepared as described in Figure 1. p34 cdc2/GST-cyclin B complexes were incubated with lysates prepared from asynchronous HeLa cells (A); HeLa cells synchronized in $\mathrm{S}$ phase (S; double thymidine block); $\mathrm{G} 2$ phase (G2; release from double thymidine into $\mathrm{H33342}$ ); or mitosis (M; mitotic shake-off following release from double thymidine block); or nocodazole arrested mitotic HeLa cells (N). Proteins were resolved by SDS-PAGE, and ${ }^{35}$ S-labeled $\mathrm{p} 34^{\mathrm{cdc2}}$ was visualized by autoradiography and quantitated by PhosphorImager. 
Thr14- and Tyr15-specific kinase activities were distinguished by using $\mathrm{p} 34^{\mathrm{cdc} 2}$ (Phe15) and $\mathrm{p} 34^{\mathrm{cdc} 2}$ (Ala14) as substrates for phosphorylation by HeLa cells synchronized in S phase, G2 phase, or mitosis. As in the case of p34 ${ }^{\text {cdc2 }}(\operatorname{Arg} 33), S-$ phase and G2-phase cells readily phosphorylated both $\mathrm{p} 34^{\text {cdc2 }}$ (Phe15) (Figure 3, middle) and $\mathrm{p} 34^{\text {cdc2 }}$ (Ala14) (Figure 3 , bottom) to the same extent as asynchronous cells. The phosphorylation of both $\mathrm{p} 34^{\text {cdc2 }}(\mathrm{Phe} 15)$ and $\mathrm{p} 34^{\mathrm{cdc} 2}(\mathrm{Ala} 14)$ by mitotic cells decreased by $\sim 65 \%$, suggesting that both Thr14and Tyr15-specific kinase activities are negatively regulated at the G2 to M phase transition. Again, these results were enhanced in nocodazole arrested HeLa cells, with no detectable phosphorylation of either $\mathrm{p} 34^{\text {cdc2 }}(\mathrm{Phe} 15)$ or $\mathrm{p} 34^{\mathrm{cdc} 2}$ (Ala14) when compared with controls. These results indicate that the kinase(s) responsible for phosphorylating $\mathrm{p} 34^{\mathrm{cdc} 2}$ on Thr14 and Tyr15 are regulated in a cell cycle dependent manner, such that both activities are reduced during mitosis.

To more closely examine the cell cycle regulation of the Thr14 and Tyr15 kinase activities, particularly at the $\mathrm{G} 2 / \mathrm{M}$ phase transition, HeLa cell lysates were assayed for their ability to phosphorylate $\mathrm{p} 34^{\mathrm{cdc}^{2}}(\operatorname{Arg} 33)$ after release from an S-phase block in the presence or the absence of the DNA binding dye, Hoechst 33342 (Figure 4A). Entry into mitosis was monitored by as-
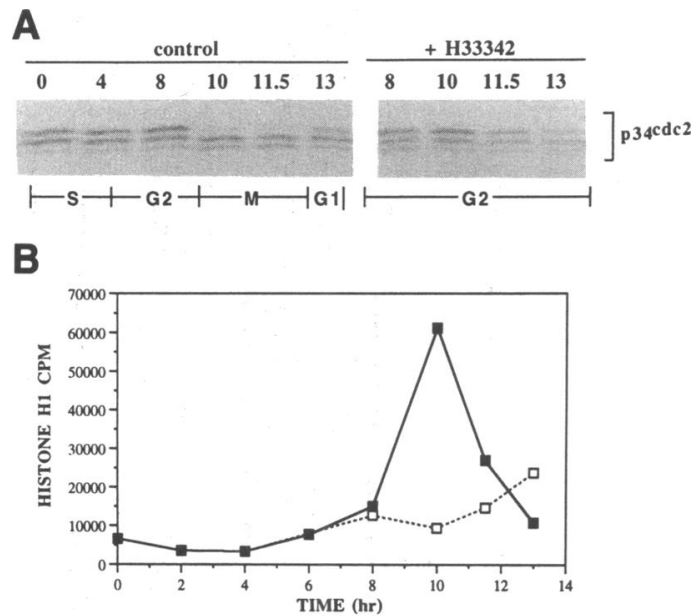

Figure 4. Cell cycle regulation of Thr14- and Tyr15-specific kinase activities in HeLa cells. HeLa cells were synchronized in S phase by a double thymidine block (time 0 ) and then allowed to progress through G2 and mitosis as described in MATERIALS AND METHODS. (A) p34 ${ }^{\text {dc2 } 2}$ (Arg33)/GST-cyclin B complexes (where p34 ${ }^{\text {dc2 } 2}$ was labeled with ${ }^{35} \mathrm{~S}$-methionine) were incubated with lysates prepared from HeLa cells that had been collected at various times after release from an $\mathrm{S}$ phase block in the absence (control lanes) or in the presence of Hoechst 33342 ( + H33342 lanes). Proteins were resolved by SDSPAGE, and ${ }^{35} \mathrm{~S}$-labeled $\mathrm{p} 34^{\text {cdc2 }}$ (Arg33) was visualized by autoradiography and quantitated by PhosphorImager. (B) HeLa cell lysates prepared as described above were immunoprecipitated with anti-cyclin $\mathrm{B}$ antiserum and precipitates were assayed for histone $\mathrm{H} 1 \mathrm{kinase}$ activity. Shown is a plot of radioactivity incorporated into histone $\mathrm{H} 1$ for control cells $(\square)$ and cells delayed in G2 (+H33342, $\square)$. saying cell lysates at selected time points for histone $\mathrm{H} 1$ kinase activity associated with anti-cyclin B immunoprecipitates (Figure 4B). Cells progressed into mitosis $10 \mathrm{~h}$ after release from the double thymidine block, and exit from mitosis was complete by $13 \mathrm{~h}$ after the release. Incubation of cells with Hoechst 33342 caused a significant G2 delay. In Figure 4A, p34 ${ }^{\text {cdc2 }}$ (Arg33) was readily phosphorylated on Thr14 and Tyr15 throughout $S$ phase and G2 phase, with $>95 \%$ of $\mathrm{p}^{34^{\text {cdc2 }}}$ (Arg33) migrating with a reduced electrophoretic mobility. Concomitant with entry of cells into mitosis, phosphorylation of $\mathrm{p} 34^{\mathrm{cdc}}$ (Arg33) at Thr14 and Tyr15 decreased to $\sim 50 \%$ of $S$ and $G 2$ phase levels. Finally, as cells exited mitosis into G1 of the next cell cycle, phosphorylation of Thr14 and Tyr15 increased, reflecting increased activity of the Thr14- and Tyr15-specific kinase(s). In the presence of $\mathrm{H} 33342$, entry into mitosis was delayed (Figure 4B) and the Thr14- and Tyr15kinase activities remained elevated (Figure 4A).

\section{Xenopus Egg Extracts also Possess Thr14- and Tyr15-Specific Kinase Activities}

Using the assay described above for HeLa cells, the characteristics of the Thr14- and Tyr15-specific kinase activities found in Xenopus egg extracts were examined. Activated Xenopus egg extracts were arrested in interphase by the addition of cycloheximide and assayed for the ability to phosphorylate several mutant forms of p34 ${ }^{\text {cdc2 }}$ in complex with GST-cyclin B (Figure 5A). Again, phosphorylation of Thr14 and/or Tyr15 was monitored by a shift in electrophoretic mobility of $\mathrm{p} 34^{\mathrm{cdc} 2}$. When

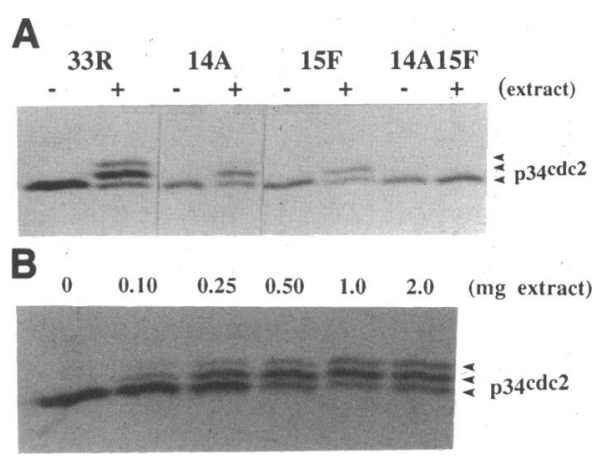

Figure 5. Characterization of Thr14- and Tyr15-specific kinase activities in Xenopus egg extracts. (A) Protein precipitates containing p34 ${ }^{\text {cdc2 }}$ (Arg33) (33R), p34 ${ }^{\text {cdc2 }}$ (Ala14) (14A), p34 ${ }^{\text {cdc2 }}$ (Phe15) (15F), p34 ${ }^{\text {cdc2 }}$ (Ala14Phe15) (14A15F) in complex with GST-cyclin B were prepared as described in Figure 1. p34 $4^{\text {cdc2 }} /$ GST-cyclin B complexes were incubated in the absence $(-)$ or in the presence $(+)$ of interphase egg extracts $(\sim 1 \mathrm{mg}$ total protein). Proteins were resolved by SDSPAGE, and ${ }^{35} \mathrm{~S}$-labeled $\mathrm{p} 34^{\text {cdc2 }}$ was visualized by autoradiography. (B) $\left({ }^{35} \mathrm{~S}\right)-\mathrm{p} 34^{\text {dc2 }}$ (Arg33)/GST-cyclin B complexes were isolated as described in Figure 1. Precipitates were then incubated with varying amounts of interphase egg extract (0-2 mg total protein). Proteins were resolved by SDS-PAGE, and ${ }^{35} \mathrm{~S}$-labeled $\mathrm{p} 34^{\text {dc2 } 2}$ was visualized by autoradiography. 
p34 ${ }^{\text {cdc2 }}$ (Arg33) was incubated with interphase extract in the presence of MgATP and vanadate, it was readily phosphorylated on both Thr14 and Tyr15, as indicated by the appearance of two slower electrophoretic forms of p34 ${ }^{\text {cdc2 }}$ (Arg33) (Figure 5A; 33R). Similarly, p34 cdc2 (Ala14) and p34 ${ }^{\text {cdc2 }}$ (Phe15) were phosphorylated on Tyr15 and Thr14, respectively, when incubated with interphase extract, indicated by a single shift in electrophoretic mobility (Figure 5A; $14 \mathrm{~A}$ and $15 \mathrm{~F}$ ). The altered mobility observed after incubation of p34 ${ }^{\text {cdc2 }}$ with interphase extract was due to phosphorylation of Thr14 and/or Tyr15, as addition of interphase extract did not alter the electrophoretic mobility of $\mathrm{p} 34^{\mathrm{cdc} 2}$ (Ala14Phe15) (Figure 5A; 14A and 15F).

To assess the activity of the Xenopus Thr14- and Tyr15-kinases, phosphorylation of Thr14 and Tyr15 was assayed with varying amounts of Xenopus egg extract. As shown in Figure 5B, the extent of phosphorylation of p34 $4^{\mathrm{cdc} 2}$ (Arg33) increased with increasing amounts of interphase extract, as measured by a decrease in electrophoretic mobility. Phosphorylation of both Thr14 and Tyr 15 was detected with as little as $100 \mu \mathrm{g}$ extract, and maximal levels of phosphorylation were achieved with 0.5 to $1.0 \mathrm{mg}$ extract. Thus, as measured in this assay, Xenopus egg extracts contain approximately twice the level of Thr14 and Tyr15 kinase activities found in HeLa cell lysates. However, it is unclear from these experiments whether this difference reflects a difference in the abundance of the Thr14/Tyr15 kinase(s), the activity of the kinase(s), or simply the method by which the extracts were prepared.

\section{Cell Cycle Regulation of Thr14- and Tyr15-Specific Kinase Activities in Xenopus Egg Extracts}

Earlier studies of the phosphorylation state of p34 cdc2 in Xenopus egg extracts suggested that the rate of phosphorylation of $\mathrm{p} 34^{\mathrm{cdc} 2}$ on Tyr15 is diminished in mitotic versus interphase extracts (Solomon et al., 1990). Smythe and Newport (1992) reported that Xenopus egg extracts naturally arrested in $M$ phase possessed less p34 ${ }^{\mathrm{cdc2}}$-specific tyrosine kinase activity than extracts arrested in S phase by the presence of aphidicolin (Smythe and Newport, 1992). To assess both the Thr14- and Tyr15-specific kinase activities at different stages of the cell cycle in Xenopus egg extracts, two approaches were taken. In one case, CSF-arrested extracts (arrested in M phase) were induced to enter interphase by the addition of $0.4 \mathrm{mM} \mathrm{CaCl}_{2}$. Extract samples were removed at selected time points after activation and incubated with $\left({ }^{35} \mathrm{~S}\right)$ p34 ${ }^{\text {cdc2 }}$ (Arg33)/GST-cyclin B complexes, MgATP, and vanadate (Figure 6A). The Thr14- and Tyr15-kinase activities were low in $\mathrm{M}$ phase extracts (Figure $6 \mathrm{~A}, 0^{\prime}$ ). Interestingly, both activities increased as early as $5 \mathrm{~min}$ after exit from $M$ phase and remained relatively constant as the extract progressed fully into interphase (Figure $6 \mathrm{~A})$.
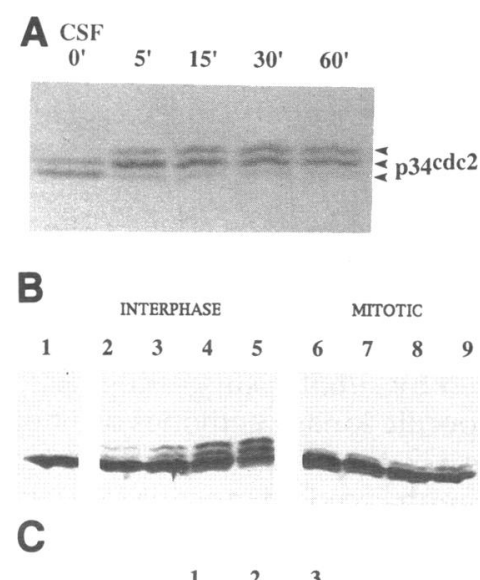

Figure 6. Cell cycle regulation of Thr14- and Tyr15-specific kinase activities in Xenopus egg extracts. $\left({ }^{35} \mathrm{~S}\right)-\mathrm{p} 34^{\text {cdc2 }}$ (Arg33)/GST-cyclin B precipitates were prepared as described in Figure 1. (A) CSF-arrested egg extracts were activated with $0.4 \mathrm{mM} \mathrm{CaCl}_{2}$ and incubated at $23^{\circ} \mathrm{C}$. Aliquots of extract were removed at $5,15,30$, and $60 \mathrm{~min}$ after activation and then incubated for $45 \mathrm{~min}$ at $25^{\circ} \mathrm{C}$ with $\left({ }^{35} \mathrm{~S}\right)$ p34 ${ }^{\text {cdc2 }}$ (Arg33)/GST-cyclin B precipitates. (B) Interphase extracts were prepared from Xenopus eggs as described in the MATERIALS AND METHODS. Mitotic extracts were prepared by the addition of $\Delta 90$ cyclin (a nondegradable form of sea urchin cyclin B) to the interphase extracts. $\left({ }^{35} \mathrm{~S}\right)-\mathrm{p} 34^{\mathrm{cdc} 2}$ (Arg33)/GST-cyclin B precipitates were incubated in the interphase (lanes 2 to 5) and mitotic (lanes 6 to 9) extracts for $5,10,15$, and $30 \mathrm{~min}$ at room temperature. Lane 1: $\left({ }^{35} \mathrm{~S}\right)$ p34 ${ }^{\text {cdc2 }}$ (Arg33)/GST-cyclin B precipitates incubated in buffer alone for $30 \mathrm{~min}$ at room temperature. (C) Interphase and mitotic extracts were assayed for their ability to phosphorylate histone H1. Lane 1: interphase extract; lane 2: interphase extract incubated at $23^{\circ} \mathrm{C}$ for $50 \mathrm{~min}$; lane 3: interphase extracts incubated at $23^{\circ} \mathrm{C}$ for $50 \mathrm{~min}$ in the presence of $\Delta 90$ sea urchin cyclin B. Proteins were resolved by SDS-PAGE, and ${ }^{35} \mathrm{~S}$-labeled $\mathrm{p} 34^{\mathrm{cdc} 2}(\mathrm{Arg} 33)$ and ${ }^{32} \mathrm{P}$-labeled histone $\mathrm{H} 1$ were visualized by autoradiography.

As a second approach, interphase extracts were prepared and were induced to enter $M$-phase by the addition of a nondegradable form of sea urchin cyclin B (Glotzer et al., 1991) (Figure 6, B and C). The extracts were then assayed for levels of histone $\mathrm{H} 1 \mathrm{ki}$ nase activity (Figure 6C) and were incubated with $\left({ }^{35} \mathrm{~S}\right)$ p34 $4^{\text {cdc2 }}$ (Arg33)/GST-cyclin B complexes for various periods of time as described above (Figure 6B). As seen in Figure 6B (lanes 2-5), interphase extracts contained Thr14- and Tyr15-kinase activities. However, when these extracts were induced to enter a stable M-phase state, a loss in both activities was observed (lanes 6 to 9). These results suggest that the Thr14- and Tyr15specific kinase activities are both activated immediately upon exit of cells from mitosis, remain high throughout interphase, and then decrease as cells progress from G2 
into mitosis. Thus the results obtained with Xenopus egg extracts parallel those obtained for HeLa cells.

\section{Characterization and Partial Purification of the Thr14/Tyr15 Kinase(s) from Xenopus Extracts}

We used the shift assay described above to begin purifying the Thr14 and Tyr15 kinases from interphase extracts prepared from Xenopus eggs (Figure 7 and 8). The assay requires the use of the $\mathrm{p} 34^{\mathrm{cdc} 2} /$ cyclin $\mathrm{B}$ complex because this is the preferred substrate for phosphorylation. Interphase extract was tested for its ability to shift the electrophoretic mobility of $\left({ }^{35} \mathrm{~S}\right)-\mathrm{p} 34^{\mathrm{cdc} 2}$ as described previously (Figure 7A, lane 1). Alternatively, interphase extract was centrifuged at $150000 \times g$, and

A

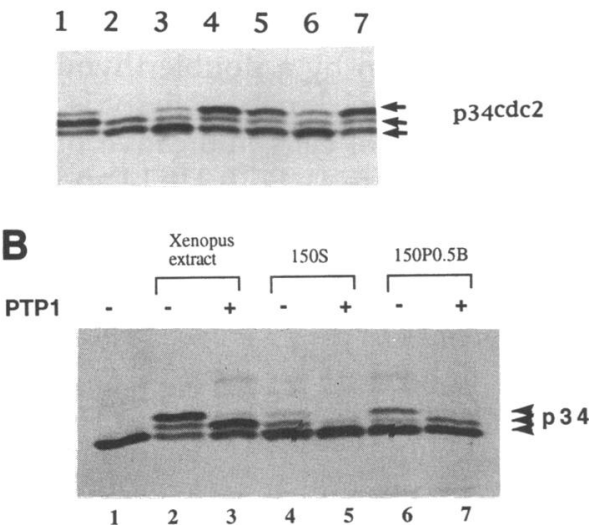

Figure 7. Identification of two activities in Xenopus interphase extracts capable of phosphorylating p34 ${ }^{\text {ddc2 }}$. (A) ${ }^{35} \mathrm{~S}$ )-p34 $4^{\text {cdc2 }}$ (Arg33)/GST-cyclin $B$ purified on glutathione beads was incubated with interphase extract prepared from Xenopus eggs (lane 1). Interphase extract was centrifuged at $150000 \times 8$. The $150000 \times 8$ supernatant fraction (lane 2) and the $150000 \times 8$ pellet fraction [extracted with varying concentrations of either Brij-35 (lanes 3-5) or Triton X (lanes 6 and 7)] were assayed for their ability to shift the electrophoretic mobility of $\left({ }^{35} \mathrm{~S}\right)-\mathrm{p} 34^{\mathrm{cdc} 2} \cdot\left({ }^{35} \mathrm{~S}\right)-\mathrm{p} 34^{\mathrm{cdc}}$ (Arg33)/GST-cyclin B was resolved by SDS-PAGE on a $12 \%$ gel. ${ }^{35} \mathrm{~S}$-labeled $\mathrm{p} 34^{\text {cdc2 }}$ was visualized by autoradiography. Lane 1: interphase extract; lane 2: $150000 \times g$ supernatant; lane 3: the $150000 \times g$ pellet was solubilized in $0.05 \%$ Brij35 , recentrifuged at $150000 \times 8$, and the supernatant was assayed; lane 4: pellet from 3 was solubilized in $0.2 \%$ Brij- 35 , was recentrifuged at $150000 \times g$ and the supernatant was assayed; lane 5: pellet from 4 was solubilized in $0.5 \%$ Brij-35, was recentrifuged at $150000 \times 8$ and the supernatant was assayed; lane 6: $150000 \times 8$ pellet was solubilized in $0.1 \%$ Triton $X$, was recentrifuged at $150000 \times g$, and the supernatant was assayed; lane 7: pellet from 6 was solubilized in $0.5 \%$ Triton $X$, was recentrifuged at $150000 \times g$, and the supernatant

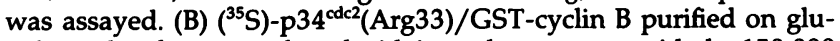
tathione beads was incubated with interphase extract, with the 150000 $\times g$ supernatant fraction (150S) or with the $150000 \times 8$ pellet fraction solubilized in $0.5 \%$ Brij-35 (150P0.5B). Reactions were stopped by washing with phosphatase buffer and further incubated in the absence (lanes 2, 4, and 6) or presence (lanes 3, 5, and 7) of PTP1. Lane 1: substrate only. $\left({ }^{35} \mathrm{~S}\right)-\mathrm{p} 34^{\mathrm{cdc} 2}$ (Arg33)/GST-cyclin B was resolved by SDS-PAGE on a $12 \%$ gel. ${ }^{35}$ S-labeled $\mathrm{p} 34^{\text {cdc2 }}$ was visualized by autoradiography.

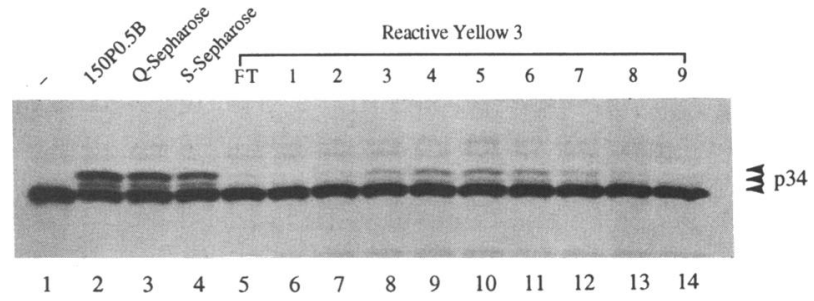

Figure 8. Partial purification of the Thr14/Tyr15 kinase(s) from Xenopus egg extract. Proteins solubilized from the $150000 \times 8$ pellet were fractionated through Q-Sepharose, S-Sepharose, and reactive yellow 3 columns. Various column fractions were assayed for the ability to phosphorylate $\left.{ }^{35} \mathrm{~S}\right)-\mathrm{p} 34^{\text {cdc2 }}$ (Arg33)/GST-cyclin B complex. Proteins were resolved by SDS-PAGE, and ${ }^{35} \mathrm{~S}$-labeled $\mathrm{p} 34^{\text {cdc2 } 2}$ was visualized by autoradiography. $\left({ }^{35} \mathrm{~S}\right)-\mathrm{p} 34^{\text {cdc2 }}(\mathrm{Arg} 33) / \mathrm{GST}-\mathrm{cyclin} \mathrm{B}$ was incubated with buffer (lane 1), the $150000 \times 8$ pellet solubilized with $0.5 \%$ Brij35 (lane 2), the Q-Sepharose pool (lane 3), the S-Sepharose pool (lane 4 ), the reactive yellow 3 flowthrough (lane 5), and the fractions of reactive yellow 3 gradient (lanes 6-14).

the supernatant fraction (Figure 7A, lane 2) or the pellet fraction [extracted with varying concentrations of either Brij-35 (lanes 3, 4, 5), or Triton $X$ (lanes 6 and 7)] were assayed for their ability to shift the electrophoretic mobility of $\left({ }^{35} \mathrm{~S}\right)-\mathrm{p} 34^{\text {cdc2 }}$. The $150000 \times g$ supernatant fraction contained an activity capable of causing a single shift in the electrophoretic mobility of $\mathrm{p} 34^{\mathrm{cdc2}}$ (this represents $\mathrm{p} 34^{\text {cdc2 }}$ singly phosphorylated on either Thr14 or Tyr15). In contrast the $150000 \times 8$ pellet contained activities (that were extractable with either Brij-35 or Triton $X$ ) that caused a double shift in the electrophoretic mobility of $\mathrm{p} 34^{\mathrm{cdc} 2}$. To further characterize these activities, phosphatase experiments were performed using PTP1, a tyrosine-specific protein phosphatase from $S$. cerevisiae (Figure 7B) (Hannig et al., 1993). p34 ${ }^{\text {cdc2 }} /$ cyclin $B$ was incubated with interphase extracts (lanes 2 and 3 ), with the $150000 \times g$ supernatant (lanes 4 and 5) or the $150000 \times g$ pellet that had been solubilized in $0.5 \%$ Brij-35. p34 cdc2/cyclin B was then incubated in phosphase buffer in the absence or the presence of PTP1. In these experiments, Tyr 15 was dephosphorylated by PTP1, whereas phosphorylated Thr14 remained intact. These experiments demonstrated that the supernatant fraction contained an activity that exclusively phosphorylated p34 ${ }^{\text {cdc2 }}$ on Tyr15 (lanes 4 and 5), whereas the pellet fraction contained activities capable of phosphorylating both Thr14 and Tyr15 (lanes 6 and 7).

To further characterize the detergent extractable activity in the pellet fraction, we used the assay conditions described above to partially purify the activities (Figure 8). The Thr14/Tyr15 kinase activities were solubilized from the $150000 \times g$ pellet by extraction with $0.5 \%$ Brij-35 and tested for their ability to shift the electrophoretic mobility of p34 ${ }^{\text {cdc2 }}$ (lane 2). Extracts were applied to a Q-Sepharose anion exchange column. Bound proteins were eluted with a gradient of $\mathrm{NaCl}(0.05$ to $1 \mathrm{M})$, and fractions were assayed for their ability to shift the electrophoretic mobility of $\mathrm{p} 34^{\mathrm{cdc} 2}$. A single peak of 
activity ( 220 to $450 \mathrm{mM} \mathrm{NaCl}$ ) was detected that catalyzed the phosphorylation of both Thr14 and Tyr15. Peak fractions were pooled (lane 3), desalted on a Sephadex G-25 column, and were then loaded onto an S-Sepharose column. The Thr14/Tyr15 kinase activities were eluted from the column with $0.3 \mathrm{M} \mathrm{NaCl}$. The SSepharose fraction (lane 4) was desalted and further applied to a reactive yellow 3 column. Proteins bound to the yellow 3 column were eluted with a $0-1 \mathrm{M} \mathrm{NaCl}$ gradient. Flow through (lane 5) and eluted fractions (lanes 6-14) were tested in the shift assay described above. Peak fractions of activity eluted between 0.15 and $0.4 \mathrm{M} \mathrm{NaCl}$. Both Thr14- and Tyr15-kinase activities co-purified through the three column steps.

\section{DISCUSSION}

This study describes the cell cycle regulation of the kinase(s) responsible for phosphorylation of $\mathrm{p} 34^{\mathrm{cdc} 2}$ on both Thr14 and Tyr15. Phosphorylation of Thr14 and/ or Tyr15 inhibits $\mathrm{p} 34^{\text {cdc2 }}$ kinase activity, and it is the abrupt dephosphorylation of these residues that triggers the activation of p34 $4^{\mathrm{cdc} 2}$ and entry of cells into mitosis (Dunphy and Newport, 1989; Gautier et al., 1989; Morla et al., 1989; Solomon et al., 1990; Krek and Nigg, 1991; Norbury et al., 1991). To monitor the phosphorylation of Thr14 and Tyr15, an assay was developed that relies on the fact that phosphorylation of $\mathrm{p} 34^{\mathrm{cdc} 2}$ on either residue results in a decrease in its electrophoretic mobility (Solomon et al., 1992). Phosphorylation of $\mathrm{p} 34^{\mathrm{cdc} 2}$ on both residues leads to a further retardation in its mobility (Solomon et al., 1992). Thus the state of phosphorylation of $\mathrm{p} 34^{\text {cdc2 }}$ (at Thr14 and Tyr15) can be monitored by changes in its electrophoretic mobility. Based on this, ${ }^{35}$ S-labeled p $34^{\text {cdc2 }}$ (in complex with GSTcyclin B) was used as a substrate for phosphorylation by various cell lysates. By using ${ }^{35} \mathrm{~S}$-labeled $\mathrm{p} 34^{\mathrm{cdc} 2}$ as a substrate, changes in electrophoretic mobility (due to phosphorylation) were easily detected by autoradiography. Furthermore, the Thr14- and Tyr15-specific kinase activities could be examined individually by monitoring changes in the electrophoretic mobility of mutant forms of $\mathrm{p} 34^{\text {cdc2 }}$ in which either Thr14 or Tyr15 was changed to a nonphosphorylatable residue. p34 ${ }^{\text {cdc2 }}$ (Ala14) and p34 ${ }^{\text {cdc2 }}$ (Phe15) each undergo a single shift in electrophoretic mobility, indicative of phosphorylation of Tyr15 and Thr14, respectively.

HeLa cells possess readily detectable Thr14 and Tyr15 kinase activities, as evidenced by the phosphorylation of $\mathrm{p} 34^{\mathrm{cdc}}$ (Arg33), as well as $\mathrm{p} 34^{\mathrm{cdc} 2}$ (Ala14) and p34 ${ }^{\text {cdc2 }}$ (Phe15) in vitro (Figures 1-3). To examine the Thr14 and Tyr15 kinase activities across the cell cycle, HeLa cells were synchronized by a double thymidine block and then allowed to progress through G2, mitosis, and into early G1. When synchronized cells were analyzed at various stages of the cell cycle, it was observed that both the Thr14 and Tyr15 kinase activities were coordinately regulated in a cell cycle-dependent manner, with both activities high until the G2/M transition (Figures 3 and 4). Upon entry of cells into mitosis, the Thr14and Tyr15-specific kinase activities were reduced. This inactivation was reversed as cells exited mitosis and progressed into G1. Interestingly, when HeLa cells were arrested in mitosis by the addition of nocodazole, the Thr14 and Tyr15 kinase activities were undetectable (Figure 3). This exaggerated inhibition of the Thr14/ Tyr15 kinase activities observed in nocodazole treated cells might be the result of an extended arrest in mitosis, leading to a cumulative inhibition or turn-over of the Thr14/Tyr15 kinases.

The Thr14 and Tyr15 kinase activities were also examined in HeLa cells that were delayed in their progression through G2 by the DNA binding dye, Hoechst 33342. Hoechst 33342 binds to DNA, and interferes with the proofreading mechanisms, which occur during G2, thus delaying the initiation of mitosis (Crissman et al., 1990). When Hoechst 33342 is added to cells following synchronization by a double thymidine block, activation of histone $\mathrm{H} 1$ kinase activity is delayed by $\geq 4 \mathrm{~h}$ relative to control cells, indicative of a delay in entry into mitosis (Figure 4). Both Thr14 and Tyr15 specific kinase activities remained high throughout this extended G2 phase, thus maintaining p34 $4^{\mathrm{cdc} 2}$ in its phosphorylated and inactive state. It is noteworthy that the activity of the Thr14/Tyr15 kinase(s) did not increase during the G2-induced delay, suggesting that normal interphase levels of Thr14 and Tyr15 kinase activities are sufficient to counteract any Cdc 25 phosphatase activity that may be present. In Xenopus, G2 delays induced by the presence of unreplicated DNA have been shown to stimulate the activity of Tyr15 kinase (Smythe and Newport, 1992) and more recently the Thr14 kinase (Kornbluth et al., 1994). Differences between the human and Xenopus results may be explained if unreplicated DNA and Hoechst binding to DNA operate to activate distinct feedback control pathways. Addressing these questions will be greatly facilitated once cDNAs encoding the Xenopus and human Thr14 and Tyr15 kinases are available.

It has been proposed that the abrupt activation of p34 ${ }^{\text {cdc2 }} /$ cyclin B at the $\mathrm{G} 2 / \mathrm{M}$ transition is triggered by the Cdc25 phosphatase, and that the activation of Cdc25 and $\mathrm{p} 34^{\mathrm{cdc} 2}$ are intertwined in an autocatalytic loop (Izumi et al., 1992; Kumagai and Dunphy, 1992; Clarke et al., 1993; Hoffmann et al., 1993). According to this model, Cdc25 dephosphorylates and activates p $34^{\text {cdc2 }}$, which then phosphorylates and further activates Cdc25 to dephosphorylate $\mathrm{p} 34^{\text {cdc2 }}$, and so on. In fact, in Xenopus and humans, Cdc25 is activated by phosphorylation (Izumi et al., 1992; Kumagai and Dunphy, 1992; Clarke et al., 1993; Hoffmann et al., 1993), and p34 ${ }^{\text {cdc2 }}$ is capable of phosphorylating and activating Cdc25 in vitro (Hoffmann et al., 1993). Based on the results obtained in this study as well as those reported by others 
(Smythe and Newport, 1992; Tang et al., 1993), it is clear that the inactivation of Thr14 and Tyr15 kinase activities also plays a role in regulating the timing of activation of p34 cdc2 at G2/M. Accordingly, the state of phosphorylation of $\mathrm{p} 34^{\text {cdc2 }}$ at Thr14 and Tyr15 is likely determined by the balance of Thr14 and Tyr15 kinase activities and $\mathrm{Cdc} 25$ phosphatase activities during late G2. Several possible mechanisms can be envisioned in which the down-regulation of the Thr14/Tyr15 kinase(s) might combine with the activation of Cdc25 and contribute to the rapid dephosphorylation and activation of $\mathrm{p} 34^{\mathrm{cdc} 2}$. One model might be that $\mathrm{Cdc} 25$ and the Thr14/Tyr15 kinase(s) are regulated by independent mechanisms which converge during late $\mathrm{G} 2$ to precisely time the activation of $\mathrm{p} 34^{\text {cdc2 }} /$ cyclin B. Alternatively, Cdc25 and the Thr14/Tyr15 kinase(s) might share a common regulator that is responsible for both activating Cdc25 and inactivating the Thr14 and Tyr15 kinase activities at the $\mathrm{G} 2 / \mathrm{M}$ transition. Interestingly, Cdc25 (from Xenopus and humans) has been shown to be activated by phosphorylation (Izumi et al., 1992; Kumagai and Dunphy, 1992; Clarke et al., 1993; Hoffmann et al., 1993), while $\mathrm{p} 107^{\text {weel }}$ (from fission yeast) is inactivated upon phosphorylation by the Cdr1/Nim1 kinase (Coleman et al., 1993; Parker et al., 1993; Wu and Russell, 1993). Furthermore, Tang et al (1993) demonstrated that fission yeast $\mathrm{p} 107^{\mathrm{wee} 1}$ is also phosphorylated and inhibited when incubated with mitotic Xenopus egg extracts, suggesting that higher eukaryotes possess kinase activity (distinct from the Cdr1/Nim1 kinase), which is capable of down-regulating p107 ${ }^{\text {weel }}$ during $M$ phase. The present evidence indicates that the Thr 14 and Tyr15 kinase activities of HeLa cells are inhibited in mitosis, and one might predict by analogy that this inhibition is due to phosphorylation of the Thr14/Tyr15 kinase(s). In that case, a common regulatory kinase and/or phosphatase could simultaneously activate the Cdc25 phosphatase and inactivate the Thr14/Tyr15 kinase(s), thus leading to an abrupt change in the phosphorylation state of $\mathrm{p} 34^{\text {cdc2 }}$ at the G2/M transition. Most likely, a combination of regulatory mechanisms is involved in the precise control of the state of phosphorylation of p34 $4^{\text {cdc2 }}$ by Cdc25 and the Thr14/Tyr15 kinase(s).

The regulation of Thr14 and Tyr15 kinase activities was examined in Xenopus egg extracts in addition to HeLa cells. Like HeLa cells, Xenopus egg extracts contained kinase activities capable of phosphorylating p34 ${ }^{\text {cdc2 }}$ on both Thr14 and Tyr15. The Xenopus Thr14/ Tyr15 kinase(s) also displayed a cell cycle dependent regulation with low activity in $\mathrm{M}$ phase. In Xenopus egg extracts, Thr14 and Tyr15 kinase activities appeared immediately upon exit from $M$ phase and entry into interphase. In addition, the activities were inhibited when interphase extracts were driven into M-phase by the addition of a nondegradable form of cyclin $B$. These findings corroborate studies reported by Solomon $e t$ al. (1990) and Smythe and Newport (1992), in which the p34 ${ }^{\text {cdc2 }}$-specific tyrosine kinase activity of Xenopus egg extracts was shown to decrease during mitosis. Of interest in the present study is the fact that Thr14-specific kinase activity is also regulated in a cell cycle dependent manner, and the regulation of its activity parallels that of the Tyr15-specific kinase activity. Similar results have recently been reported by Kornbluth et al. (1994). These results suggest that Thr14 and Tyr15 kinase activities are regulated in a similar manner throughout the cell cycle. Given that Thr14 and Tyr15 specific kinase activities are diminished during mitosis in both Xenopus and HeLa cells, and that fission yeast $\mathrm{p} 107^{\text {weel }}$ is also inhibited in the context of an M phase extract (Tang et al., 1993), down-regulation of the kinase(s) responsible for the inhibitory phosphorylation of $\mathrm{p} 34^{\text {cdc2 }}$ may represent a conserved mechanism by which activation of p $34^{\text {cdc2 }}$ and entry of cells into mitosis is regulated. Xenopus egg extracts should be readily amenable to dissecting the cell cycle regulation of the Thr14 and Tyr15 kinases at the biochemical level.

To date, only a single human kinase capable of phosphorylating $\mathrm{p} 34^{\mathrm{cdc} 2}$ on Tyr15 and inhibiting the $\mathrm{p} 34^{\mathrm{cdc} 2} /$ cyclin B complex has been identified (Honda et al., 1992; Parker et al., 1992; McGowen and Russell, 1993). The gene encoding this kinase (denoted WEE1Hu) was identified in a genetic screen looking for functional homologs of wee1+ (Igarashi et al., 1991). The kinase responsible for Thr14 phosphorylation has not been identified. We have detected two activities capable of phosphorylating $\mathrm{p} 34^{\text {cdc2 }}$ on Thr14 and Tyr15 in interphase extracts prepared from Xenopus eggs. An activity capable of phosphorylating Tyr 15 remains soluble after centrifugation of interphase extracts at $150000 \times \mathrm{g}$. A second activity capable of phosphorylating both Thr14 and Tyr15 pellets during the $150000 \times g$ spin but is detergent extractable. Similar findings have recently been reported by Kornbluth et al. (1994). We have begun to biochemically purify the detergent extractable enzyme. The assay requires the use of the $\mathrm{p} 34^{\mathrm{cdc}} /$ cyclin $B$ complex as this is the preferred substrate for phosphorylation. The kinases are detected in various fractions based on their ability to cause a shift in the electrophoretic mobility of $\mathrm{p} 34^{\text {cdc2 }}$ on SDS-gels. The kinases co-purify through three successive chromatographic steps. Further steps will be required to purify the enzyme(s) to homogeneity for future study, but the intriguing possibility exists that a dual-specificity kinase capable of phosphorylating p34 $4^{\text {cdc2 }}$ on both Thr14 and Tyr15 is present in higher eukaryotic cells.

\section{ACKNOWLEDGMENTS}

The authors thank Dr. Peter Jackson for supplying Xenopus extracts and for advice with the Xenopus studies. This work was supported by the National Institutes of Health and by a grant from the Lucille P. Markey Charitable Trust. H.P.-W. is a Pew Scholar in the Biomedical Sciences and an Investigator of the Howard Hughes Medical Institute. 


\section{REFERENCES}

Atherton-Fessler, S., Parker, L.L., Geahlen, R.L., and Piwnica-Worms, H. (1993). Mechanisms of p34cdc2 regulation. Mol. Cell. Biol. 13, 1675-1685.

Clarke, P.R., Hoffman, I., Draetta, G., and Karsenti, E. (1993). Dephosphorylation of cdc $25 \mathrm{C}$ by a type-2A protein phosphatase: specific regulation during the cell cycle in Xenopus egg extracts. Mol. Biol. Cell 4, 397-411.

Coleman, T.R., Tang, Z., and Dunphy, W.G. (1993). Negative regulation of the wee1 protein kinase by direct action of the nim1/cdr1 mitotic inducer. Cell 72, 919-929.

Crissman, H.A., Hofland, M.H., Stevenson, A.P., Wilder, M.E., and Tobey, R.A. (1990). Supravital cell staining with Hoechst 33342 and DiOC5(3). Methods Cell Biol. 33, 89-95.

Draetta, G., and Beach, D. (1988). Activation of cdc2 protein kinase during mitosis in human cells: cell cycle-dependent phosphorylation and subunit rearrangement. Cell 54, 17-26.

Draetta, G., Piwnica-Worms, H., Morrison, D., Druker, B., Roberts, T., and Beach, D. (1988). Human cdc2 protein kinase is a major cellcycle regulated tyrosine kinase substrate. Nature 336, 738-744.

Ducommun, B., Draetta, G., Young, P., and Beach, D. (1990). Fission yeast cdc25 is a cell cycle regulated protein. Biochem. Biophys. Res. Comm. 167, 301-309.

Dunphy, W., and Newport, J. (1989). Fission yeast p13 blocks mitotic activation and tyrosine dephosphorylation of the Xenopus cdc2 protein kinase. Cell 58, 181-191.

Dunphy, W.G., and Kumagai, A. (1991). The cdc25 protein contains an intrinsic phosphatase activity. Cell 67, 189-196.

Edgar, B.A., and O'Farrell, P.H. (1989). Genetic control of cell division patterns in the Drosophila embryo. Cell 57, 177-187.

Edgar, B.A., and O'Farrell, P.H. (1990). The three postblastoderm cell cycles of Drosophila embryogenesis are regulated in G2 by string. Cell 62, 469-480.

Featherstone, C., and Russell, P. (1991). Fission yeast p107wee1 mitotic inhibitor is a tyrosine/serine kinase. Nature 349, 808-811.

Galaktionov, K., and Beach, D. (1991). Specific activation of cdc25 tyrosine phosphatases by B-type cyclins: evidence for multiple roles of mitotic cyclins. Cell 67, 1181-1194.

Gautier, J., Matsukawa, T., Nurse, P., and Maller, J. (1989). Dephosphorylation and activation of Xenopus $\mathrm{p} 34 \mathrm{cdc} 2$ protein kinase during the cell cycle. Nature 339, 626-629.

Gautier, J., Solomon, M.J., Booher, R.N., Bazan, J.F., and Kirschner, M.W. (1991). cdc25 is a specific tyrosine phosphatase that directly activates p3cdc2. Cell 67, 197-211.

Glotzer, M., Murray, A.W., and Kirschner, M.W. (1991). Cyclin is degraded by the ubiquitin pathway. Nature 349, 132-138.

Hannig, G., Ottilie, S., Schievella, A.R., and Erikson, R.L. (1993). Comparison of the biochemical and biological functions of tyrosine phosphatases from fission yeast, budding yeast and animal cells. Yeast 9, 1039-1052.

Hoffmann, I., Clarke, P.R., Marcote, M.J., Karsenti, E., and Draetta, G. (1993). Phosphorylation and activation of human cdc25-C by cdc2cyclin B and its involvement in the self-amplification of MPF at mitosis. EMBO J. 12, 53-63.

Honda, R., Ohba, Y., and Yasuda, H. (1992). The cell cycle regulator, human p50wee1, is a tyrosine kinase and not a serine/tyrosine kinase. Biochem. Biophys. Res. Comm. 186, 1333-1338.

Igarashi, M., Nagata, A., Jinno, S., Suto, K., and Okayama, H. (1991). Wee1+-like gene in human cells. Nature 353, 80-83.
Izumi, T., Walker, D.H., and Maller, J.L. (1992). Periodic changes in phosphorylation of the Xenopus cdc 25 phosphatase regulate its activity. Mol. Biol. Cell 3, 929-939.

Jessus, C., and Beach, D. (1992). Oscillation of MPF is accompanied by periodic association between cdc25 and cdc2-cyclin B. Cell 68 , 323-332.

Kornbluth, S., Sebastian, B., Hunter, T., and Newport, J. (1994). Membrane localization of the kinase which phosphorylates p34cdc2 on threonine 14. Mol. Biol. Cell 5, 273-282.

Krek, W., and Nigg, E.A. (1991). Differential phosphorylation of vertebrate p34cdc2 kinase at the G1/S and G2/M transitions of the cell cycle: identification of major phosphorylation sites. EMBO J. 10, 305316.

Kumagai, A., and Dunphy, W.G. (1992). Regulation of the cdc25 protein during the cell cycle in Xenopus extracts. Cell 70, 139-151.

Lee, M.S., Ogg, S., Xu, M., Parker, L.L., Donoghue, D.J., Maller, J.L., and Piwnica-Worms, H. (1992). cdc25+ encodes a protein phosphatase that dephosphorylates p34cdc2. Mol. Biol. Cell 3, 73-84.

Lorca, T., Labbe, J.-C., Devault, A., Fesquet, D., Capony, J.-P., Cavadore, J.-C., Le Bouffant, F., and Doree, M. (1992). Dephosphorylation of cdc2 on threonine 161 is required for cdc2 kinase inactivation and normal anaphase. EMBO J. 11, 2381-2390.

Lundgren, K., Walworth, N., Booher, R., Dembski, M., Kirschner, M., and Beach, D. (1991). mik1 and wee1 cooperate in the inhibitory tyrosine phosphorylation of cdc2. Cell 64, 1111-1122.

McGowen, C.H., and Russell, P. (1993). Human Wee1 kinase inhibits cell division by phosphorylating p34cdc2 exclusively on Tyr15. EMBO J. 12, 75-85.

Meijer, L., Azzi, L., and Wang, J.Y.J. (1991). Cyclin B targets p34cdc2 for tyrosine phosphorylation. EMBO J. 10, 1545-1554.

Millar, J.B.A., Blevitt, J., Gerace, L., Sadhu, K., Featherstone, C., and Russell, P. (1991b). p55CDC25 is a nuclear protein required for the initiation of mitosis in human cells. Proc. Natl. Acad. Sci. USA 88, 10500-10504.

Millar, J.B.A., Lenaers, G., and Russell, P. (1992). Pyp3 PTPase acts as a mitotic inducer in fission yeast. EMBO J. 11, 4933-4941.

Millar, J.B.A., McGowan, C.H., Lenaers, G., Jones, R., and Russell, P. (1991a). p80cdc25 mitotic inducer is the tyrosine phosphatase that activates p34cdc2 kinase in fission yeast. EMBO J. 10, 4301-4309.

Moreno, S., Nurse, P., and Russell, P. (1990). Regulation of mitosis by cyclic accumulation of $\mathrm{p} 80 \mathrm{cdc} 25$ mitotic inducer in fission yeast. Nature 344, 549-552.

Morla, A., Draetta, G., Beach, D., and Wang, J. (1989). Reversible tyrosine phosphorylation of cdc2: dephosphorylation accompanies activation during entry into mitosis. Cell 58, 193-203.

Motokura, T., Bloom, T., Kim, H.G., Juppner, H., Ruderman, J.V., Kronenberg, H.M., and Arnold, A. (1991). A novel cyclin encoded by a bc11-linked candidate oncogene. Nature 350, 512-515.

Murray, A.W. (1991). Cell cycle extracts. In: Xenopus laevis: Practical Uses in Cell and Molecular Biology, eds. B.K. Kay and H.B. Peng. San Diego: Academic Press, 581-605.

Murray, A.W., and Kirschner, M.W. (1989). Cyclin synthesis drives the early embryonic cell cycle. Nature 339, 275-280.

Norbury, C., Blow, J., and Nurse, P. (1991). Regulatory phosphorylation of the p34cdc2 protein kinase in vertebrates. EMBO J. 10, 33213329.

Parker, L.L., Atherton-Fessler, S., Lee, M.S., Ogg, S., Falk, F.L., Swenson, K.I., and Piwnica-Worms, H. (1991). Cyclin promotes the tyrosine phosphorylation of p34cdc2 in a wee1+ dependent manner. EMBO J. 10, 1255-1263. 
Parker, L.L., Atherton-Fessler, S., and Piwnica-Worms, H. (1992). p107wee1 is a dual-specificity kinase that phosphorylates p34cdc2 on tyrosine 15. Proc. Natl. Acad. Sci. USA 89, 2917-2921.

Parker, L.L., and Piwnica-Worms, H. (1992). Inactivation of the p34cdc2/cyclin B complex by the human WEE1 tyrosine kinase. Science 257, 1955-1957.

Parker, L.L., Walter, S.A., and Piwnica-Worms, H. (1993). Phosphorylation and inactivation of p107wee1 by the nim1/cdr1 kinase. Nature 363, 736-738.

Piwnica-Worms, H. (1990). Expression of proteins in insect cells using baculovirus vectors. In: Current Protocols in Molecular Biology, eds. F.M. Ausubel, R. Brent, R.E. Kingston, D.D. Moore, J.G. Seidman, J.A. Smith, and K. Struhl. New York: Greene Publishing Associates, 16.

Russell, P., and Nurse, P. (1986). cdc25+ functions as an inducer in the mitotic control of fission yeast. Cell 45, 145-153.

Russell, P., and Nurse, P. (1987). Negative regulation of mitosis by wee1 + , a gene encoding a protein kinase homolog. Cell 45, 559-567.

Sebastian, B., Kakizuka, A., and Hunter, T. (1993). Cdc25M2 activation of cyclin-dependent kinases by dephosphorylation of threonine 14 and tyrosine 15. Proc. Natl. Acad. Sci, USA 90, 3521-3524.
Smythe, C., and Newport, J.W. (1992). Coupling of mitosis to the completion of $\mathrm{S}$ phase in Xenopus occurs via modulation of the tyrosine kinase that phosphorylates p34cdc2. Cell 68, 787-797.

Solomon, M.J., Glotzer, M., Lee, T.H., Philippe, M., and Kirschner, M.W. (1990). Cyclin activation of p34cdc2. Cell 63, 1013-1024.

Solomon, M.J., Lee, T., and Kirschner, M.W. (1992). The role of phosphorylation in p34cdc2 activation: identification of an activating kinase. Mol. Biol. Cell 3, 13-27.

Strausfeld, U., Labbe, J.C., Fesquet, D., Cavadore, J.C., Picard, A., Sadhu, K., Russell, P., and Doree, M. (1991). Dephosphorylation and activation of a p34cdc2/cyclin B complex in vitro by human CDC25 protein. Nature 351, 242-245.

Tang, Z., Coleman, T.R., and Dunphy, W.G. (1993). Two distinct mechanisms for negative regulation of the Wee1 protein kinase. EMBO J. 12, 3427-3436.

Wu, L., and Russell, P. (1993). Nim1 kinase promotes mitosis by inactivating Wee1 tyrosine kinase. Nature 363, 738-741.

Zheng, X.-F., and Ruderman, J.V. (1993). Functional analysis of the $P$ Box, a domain in cyclin B required for the activation of Cdc25. Cell 75, 155-164. 